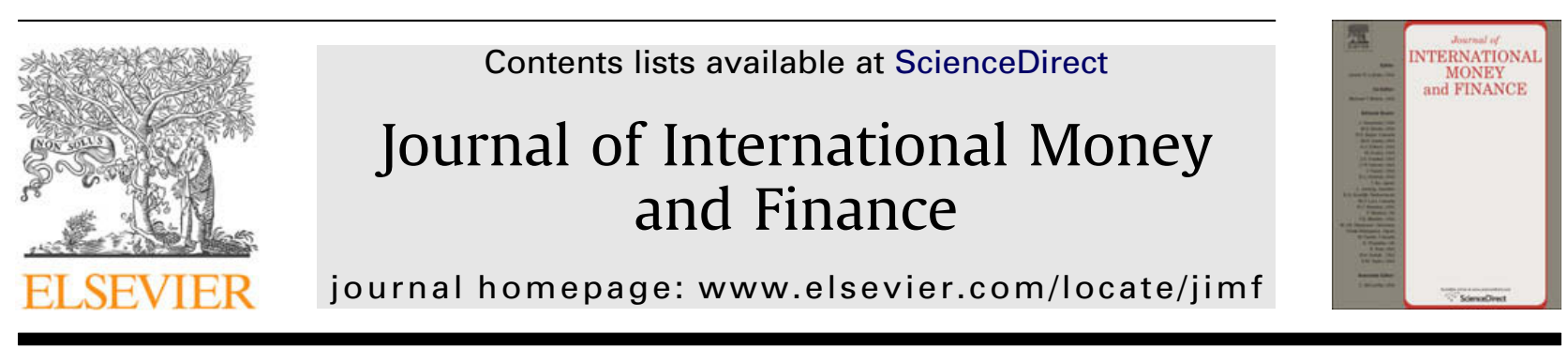

\title{
A model of asset pricing under country risk
}

\author{
Sandro C. Andrade* \\ School of Business Administration, University of Miami, P.O. Box 248094, Coral Gables, FL 33124-6552, United States
}

JEL classification:

F21

F34

G12

G15

Keywords:

Sovereign spread

Asset pricing

Emerging market discount

\section{A B S T R A C T}

$\overline{\text { I develop a formal model that could provide quantitative guidance }}$ to practitioners who use sovereign yield spreads in emerging market asset valuation. The model provides analytical formulas relating emerging market stock $\mathrm{P} / \mathrm{E}$ ratios (and expected returns) to the corresponding average yield spread in sovereign bonds. In the model, sovereign yield spreads carry information about the likelihood of a negative regime change in an emerging market ("country risk"), under the common assumption that the regime change is associated with a hostile renegotiation of the country's foreign debt. In the model, country risk is priced because the regime change may be endogenously associated with bad states of the global economy. Data from emerging markets are consistent with some of the model's quantitative and qualitative predictions. (c) 2009 Elsevier Ltd. All rights reserved.

\section{Introduction}

Practitioners typically use yield spreads on sovereign bonds to value emerging market assets based on "adjusted" versions of the World CAPM (Keck et al., 1998; Estrada, 2007). Although motivated by sound economic intuition, these adjustments lack any theoretical foundation and rely on insufficient empirical evidence. Practitioners cannot easily borrow from the academic literature, since it has not yet produced an emerging market asset pricing model that is both widely accepted and suitable for practical use. Indeed, Bekaert and Harvey (2002) summarize the state of asset valuation in emerging markets affirming that such markets "provide a challenge to existing models and beg the creation of new models". My main contribution is to develop the first structural model of sovereign default allowing for simultaneous pricing of emerging market sovereign bonds and stocks. The model has analytical formulas for stock $\mathrm{P} / \mathrm{E}$ ratios and expected returns as functions of sovereign yield spreads.

\footnotetext{
* Tel.: +1 3052848819.

E-mail address: sca@miami.edu
} 
These formulas could provide quantitative guidance to practitioners who use sovereign yield spreads in emerging market asset valuation.

In my model, the price of an emerging market stock is the appropriately discounted present value of a stochastically growing perpetuity whose trend and volatility may undergo a negative regime change. This "country risk" regime change is caused by a hostile renegotiation of foreign debt a la Argentina. The regime change can be either endogenous, stemming from a rational decision to initiate the debt renegotiation, or exogenous, resulting from a shock to sovereign rulers' preferences. Sovereign yield spreads are useful measures of "country risk" because they contain relevant information about the timing of the negative regime change.

Because of country risk, emerging market stocks are valued at a discount, i.e., lower P/E ratios, than otherwise identical stocks that are not subject to country risk. I provide an analytical formula for this discount. In my model, the discount reflects not only the probability of a negative regime change but also global risk aversion. That is, country risk is priced. Country risk receives compensation because an endogenous regime change is likely to occur in bad states of the global economy. I also provide an analytical formula for the instantaneous minimum variance hedge ratio between emerging market stocks and sovereign bonds, which could be useful in relative trading strategies.

I assume that emerging stock markets are fully integrated to global financial markets: the same global pricing kernel prices all securities. This contrasts with recent work by Bekaert et al. (2008). While I explain changes in the emerging market discount with changes in the likelihood of a regime change in cash flows and changes in the systematic risk of emerging market stocks, Bekaert et al. (2008) rely on changes on the pricing kernel that applies to emerging market stocks. These pricing kernel changes are motivated by time-varying market segmentation: sometimes emerging market stocks are priced primarily by local investors, and sometimes primarily by foreign investors, who are assumed to price stocks differently from local ones.

I assess some of my model's predictions using data from nine emerging markets. Most regressions support the model's qualitative predictions regarding the relationship between second moments of returns and sovereign yield spreads. ${ }^{1}$ Such regressions confirm that, as sovereign yield spreads increase, emerging market stocks become more volatile in absolute terms, less volatile relative to sovereign bonds, and more correlated with sovereign bonds (Table 2). Furthermore, my model, calibrated with reasonable parameters, can match Brazil's median stock return volatility, median ratio of sovereign bond and stock volatilities, and median correlation between stocks and sovereign bonds (Table 3).

\subsection{Related literature}

Much of the existing literature in emerging stock markets analyzes their integration (or lack of) to global financial markets. Until the early nineties most emerging countries imposed severe restrictions on foreign ownership of equity. Stulz (1981) and Errunza and Losq (1985) show that ownership restrictions prevent the equalization of risk prices across countries because some investors are not allowed to fully diversify their portfolios. Several authors document the behavior of emerging market stocks under partial market integration - see, for example, Bailey and Jagtiani (1994), Bekaert (1995), Harvey (1995), Bekaert and Harvey (1995), Domowitz et al. (1997), Bailey et al. (1999), and Bonomo and Garcia (2001).

During the late eighties and early nineties most emerging countries either eliminated or drastically reduced restrictions on foreign ownership (Edison and Warnock, 2003). Many papers analyze the impact of such equity liberalization on asset prices and economic growth. Some important examples are Bekaert and Harvey (1997, 2000, 2003), Errunza and Miller (2000), Henry (2000), Phylaktis and Ravazzolo (2002), Bekaert et al. (2002), Martell and Stulz (2003), and Chari and Henry (2004).

\footnotetext{
${ }^{1}$ It is important to mention that I do not compare the physical hostile renegotiation probabilities implied by my model to hostile renegotiation frequencies realized in the data. See Huang and Huang (2003) and Leland (2004) for such comparison using a structural model of corporate bond pricing. This important alternative form of model validation is left for future research.
} 
Empirical research, however, shows that emerging market stock returns are still substantially influenced by country-specific factors - see Erb et al. (1995, 1996), Bekaert et al. (1997), Nishiotis (2004), Carrieri et al. (2006), Carrieri et al. (2007), and Bekaert et al. (2007, 2008). My paper is allied with a recent literature that models specific features of emerging markets in an attempt to explain the behavior of their asset prices. Important examples include Goetzmann and Jorion (1999), Cherian and Perotti (2001), Bansal and Dahlquist (2002), Stulz (2005), and Albuquerque and Wang (2008). Like Goetzmann and Jorion (1999), I work under the null hypothesis of full market integration and focus on the return generating process of emerging market stocks. Inspired by Erb et al. (1995, 1996a,b), I associate emerging market stock returns with a measure of "country risk".

My model has an exogenous pricing kernel and its results are driven by the existence of a real option. These features are shared with structural models of corporate debt valuation, such as Leland (1994), and with influential papers in asset pricing like Berk et al. (1999). In my model, results are driven by sovereign rulers' option to promote a hostile renegotiation of foreign debt. ${ }^{2}$

In my model, sovereign default/renegotiation occurs after bad endowment shocks and has negative implications for subsequent economic growth (i.e., causes a negative macroeconomic regime change). Several models of sovereign default/renegotiation share both of these features. Early examples include Eaton and Gersovitz (1981), Cohen and Sachs (1985), Kulatilaka and Marcus (1987) and Bulow and Rogoff (1989). Recent examples include Arellano (2008), Aguiar and Gopinath (2006), and Yue (2006). In contrast to these previous authors, I focus on the asset pricing implications of the option to default/ renegotiate sovereign debt, rather than on matching moments of macroeconomic variables. The next section describes the model and discusses its results.

\section{Model} (GBM):

Consider an emerging country whose gross endowment $Y_{t}$ follows a Geometric Brownian Motion

$$
\frac{d Y_{t}}{Y_{t}}=\mu_{y} d t+\sigma_{y} d Z_{t}^{y}
$$

The country has debt requiring a constant payment $c>0$. Therefore, the net endowment is $Y_{t}-c$. Endowment is composed of dividends and other sources of non-financial income, such as labor income. The earnings flow of a generic stock in the emerging market, denoted by $X_{t}$, also follows a GBM:

$$
\frac{d X_{t}}{X_{t}}=\mu_{x} d t+\sigma_{x} d Z_{t}^{x}
$$

Earnings and endowment are positively correlated: $(1 / d t)\left(d Z_{t}^{X}\right)\left(d Z_{t}^{y}\right)=\rho_{x y}>0$. Following Bakshi and Chen (2005), I abstract from corporate dividend policy and equate stock dividends to stock earnings.

The sovereign bond market and the emerging stock market are integrated. All securities are priced by the same global pricing kernel $\Lambda_{t}$, which also follows a GBM:

$$
\frac{d \Lambda_{t}}{\Lambda_{t}}=-r d t-\lambda d Z_{t}^{\Lambda} .
$$

The trend of the pricing kernel is the international risk-free rate, and its volatility is the maximum Sharpe Ratio attainable by forming global securities' portfolios. ${ }^{3}$ The pricing kernel is negatively correlated with both the endowment and the dividends: $(1 / d t)\left(d Z_{t}^{X}\right)\left(d Z_{t}^{\Lambda}\right)=\rho_{y}>0$ and $(1 / d t)\left(d Z_{t}^{X}\right)\left(d Z_{t}^{\Lambda}\right)=\rho_{x}>0$. Such

\footnotetext{
2 This paper is also related to literature on sovereign debt pricing. Work in this area includes Claessens and Pennacchi (1996), Hayri (2000), Westphalen (2001), Duffie et al. (2003), François (2006), Pan and Singleton (2008), Hilscher and Nosbusch (2007) and Remolona et al. (2008).

${ }^{3}$ For example, if the World CAPM holds, $\lambda$ is the Sharpe Ratio of the World Market Portfolio, and $d Z_{t}^{\lambda}$ is the unexpected continuously compounded return on the World Market Portfolio divided by its standard deviation.
} 
positive correlations reflect the fact that economic growth in emerging market economies is positively correlated with global economic growth. The following restriction guarantees that present values are finite: $r>\mu_{x}-\lambda \rho_{x} \sigma_{x}$.

The emerging country is governed by risk-neutral rulers with time preference parameter $\delta>\mu_{y}$. The rulers have the option to promote one (and only one) hostile renegotiation of the country's foreign debt. As a result of this renegotiation, the perpetual debt payment is reduced to $0<\bar{c}<c$. The high debt service $c$ is potentially sustainable in equilibrium because the hostile renegotiation is costly: the endowment growth trend falls to $\overline{\mu_{y}}<\mu_{y}$ after the hostile renegotiation. ${ }^{4}$ The growth trend of the generic stock decreases to $\overline{\mu_{x}} \leq \mu_{x}$ and its growth volatility increases to $\overline{\sigma_{x}} \geq \sigma_{x}$. The model is agnostic about the causes of the reduction in the stock earnings drift. In particular, the drift reduction can be due not only to a reduction of the country's macroeconomic growth rate, but also to government expropriation. None of the benefits associated with the debt service reduction accrues to stockholders (for example, the reduction in foreign debt service gives rise to a reduction of labor income taxes).

The emerging country government chooses the hostile renegotiation time $T$ in order to maximize the present value of net endowment. The government's problem at time $t$ is:

$$
\sup _{T}\left\{E_{t}\left[\int_{t}^{T} e^{-\delta(s-t)}\left(Y_{S}-c\right) \mathrm{d} s\right]+E_{t}\left[\int_{T}^{\infty} e^{-\delta(s-t)}\left(Y_{S}-\bar{c}\right) \mathrm{d} s\right]\right\} .
$$

Proposition 1 shows how sovereign rulers balance the benefit of an immediate reduction in foreign debt service versus the cost of a lower endowment growth trend following the hostile renegotiation.

Proposition 1. For an emerging market ruler with time preference $\delta$, the optimal hostile renegotiation time is the first time that gross endowment $Y_{t}$ hits a lower boundary $\bar{Y}$ given by

$$
\bar{Y}=\frac{\theta}{\theta+1}(c-\bar{c}) \frac{\left(\delta-\mu_{y}\right)\left(\delta-\overline{\mu_{y}}\right)}{\delta\left(\mu_{y}-\overline{\mu_{y}}\right)},
$$

and

$$
\theta=\frac{1}{2}-\frac{\mu_{y}}{\sigma^{2}}-\sqrt{\left(\frac{1}{2}-\frac{\mu_{y}}{\sigma_{y}^{2}}\right)^{2}+\frac{2 \delta}{\sigma_{y}^{2}}}<0 .
$$

Proof. See Appendix A.

Equation (1) defines the maximum ratio of foreign debt service to gross endowment $c / \bar{Y}$ that sovereign rulers are willing to bear. Using Equation (1), it can be shown that more patient rulers accept higher debt service ratios.

For exogenous political economy reasons, the time preference parameter of sovereign rulers may suddenly jump from $\delta$ to infinity. In that case, rulers promote the hostile renegotiation of foreign debt immediately, regardless of the ratio of foreign debt service to endowment. This preference shock is governed by a Poisson process with parameter $\eta-$ i.e., there is a $\eta d t$ probability that the shock will occur in the next interval $d t$.

The prices of emerging market securities reflect the possibility of a negative macroeconomic regime change associated with the hostile renegotiation of foreign debt. I refer to this possibility as "country

\footnotetext{
${ }^{4}$ Commenting on the sustainability of sovereign debt markets, Eaton and Fernandez (1995) write: "an immediate implication [of the non-enforceability of sovereign debt] is that the country's desire to avoid some sanction if it fails to repay, or to obtain a reward if it repays, must be central." The common assumption that sovereign default has negative implications for subsequent economic performance is based on the fact that there is a market for sovereign debt, even though sovereign debt is non-enforceable. See also Dooley (2000) and Rose (2005).
} 
risk". The regime change can be either endogenous, when endowment hits the lower barrier $\bar{Y}$, or exogenous, when sovereign rulers suddenly become infinitely impatient and promote the hostile renegotiation of debt immediately.

First I price sovereign debt, then I price emerging market stocks. I adopt Leland's (1998) framework that allows for constant total debt payments with finite maturity debt. Before the hostile renegotiation, the total foreign debt service $c$ is composed of coupon and principal payments. At each moment in time the country retires a fraction $m$ of its total debt, and replaces it by newly issued debt with the same principal value and coupon rate. New debt is issued at market value, which may be different from par value. In the absence of hostile renegotiation, debt issued at time 0 has remaining principal $e^{-m t} p$ and pays cash flow $e^{-m t}\left(c_{p}+m p\right)$ at time $t$. Leland (1998) shows that the total debt payment at time $t$ is constant and given by $c=c_{p}+m p$, and that the average debt maturity in the absence of hostile renegotiation is $1 / \mathrm{m}$. When the hostile renegotiation occurs, the entire debt outstanding is substituted by new debt with lower principal $\bar{p}=(\bar{c} / c) p$ and lower coupon $\overline{c_{p}}=(\bar{c} / c) c_{p}$. As before, a fraction $m$ of the renegotiated debt is continuously rolled-over after renegotiation, so that the total debt payment is constant at $\bar{c}=\overline{c_{p}}+m \bar{p}$ even though the average debt maturity $1 / m$ is finite. Proposition 2 below has the value of total outstanding sovereign debt and its associated average yield spread.

Proposition 2. The total value of outstanding sovereign debt is

$$
B_{t}=-\left(\frac{Y_{t}}{\bar{Y}}\right)^{\beta}\left(\frac{c-\bar{c}}{r+\eta+m}\right)+\frac{\frac{\eta \bar{c}}{r+m}+c}{r+\eta+m}
$$

where

$$
\beta=\frac{1}{2}-\frac{\mu_{y}-\lambda \sigma_{y} \rho_{y}}{\sigma_{y}^{2}}-\sqrt{\left(\frac{1}{2}-\frac{\mu_{y}-\lambda \sigma_{y} \rho_{y}}{\sigma_{y}^{2}}\right)^{2}+\frac{2}{\sigma_{y}^{2}}(r+\eta) .}
$$

The average yield spread on outstanding sovereign debt is

$$
S_{t}=\frac{r+\eta+m}{1+\frac{\eta \bar{c}}{r+m}-\left(1-\frac{\bar{c}}{c}\right)\left(\frac{Y_{t}}{\bar{Y}}\right)^{\beta}}-r-m .
$$

Proof. See Appendix A.

Equation (4) shows that $Y_{t}$ and $S_{t}$ are inversely related. Using Equation (4), I compute the maximum spread $(r+m)((c / \bar{c})-1)$ when $Y_{t} \rightarrow \bar{Y}$ and the minimum spread $[\eta(1-(\bar{c} / c))] /(1+(\eta /(r+m))(\bar{c} / c))$ when $Y_{t} \rightarrow \infty$. Using the parameters in Table 2, the minimum spread is 0.0089 and the maximum spread is 0.6125 . Note that the sovereign spread $S_{t}$ depends on $\rho_{y} \lambda$ through $\beta$. Therefore, the spread reflects not only country risk (i.e., the probability of hostile renegotiation and the associated loss), but also global risk aversion. ${ }^{5}$

\subsection{Stock valuation}

In Propositions 1 and 2 I derive the average yield spread on sovereign bonds as a function of model parameters. In this section I relate stock prices to sovereign spreads. The section is organized as follows: Propositions 3 and 4 have formulas for the stock P/E ratio and the value discounts respectively, and Propositions 5 and 6 have formulas for the instantaneous second moments of stock returns and the instantaneous expected stock return respectively.

\footnotetext{
${ }^{5}$ See Remolona et al. (2008) for an empirical decomposition of sovereign spreads into expected loss and risk premium components.
} 
Proposition 3. The price-earnings ratio of the emerging market stock decreases with the average sovereign yield spread $S_{t}$ and is given by

$$
\begin{aligned}
\frac{P_{t}}{X_{t}}\left(S_{t}\right)= & \left.\frac{1}{\left(r+\eta+\lambda \rho_{x} \sigma_{x}-\mu_{x}\right)\left(r+\lambda \rho_{x} \overline{\sigma_{x}}-\overline{\mu_{x}}\right.}\right) \\
& \times\left(r+\eta+\lambda \rho_{x} \overline{\sigma_{x}}-\overline{\mu_{x}}-\left[\frac{S_{t}\left(\frac{1+\frac{\eta}{r+m} \frac{\bar{c}}{\bar{c}}}{1-\frac{\bar{c}}{c}}\right)-\eta}{S_{t}+r+m}\right]^{\frac{\alpha}{\beta}}\left[\mu_{x}-\overline{\mu_{x}}+\lambda \rho_{x}\left(\overline{\sigma_{x}}-\sigma_{x}\right)\right]\right),
\end{aligned}
$$

where

$$
\alpha=\frac{1}{2}-\frac{\mu_{y}-\lambda \sigma_{y} \rho_{y}}{\sigma_{y}^{2}}-\frac{\rho_{x y} \sigma_{x}}{\sigma_{y}}-\sqrt{\left[\frac{1}{2}-\frac{\mu_{y}-\lambda \sigma_{y} \rho_{y}}{\sigma_{y}^{2}}-\frac{\rho_{x y} \sigma_{x}}{\sigma_{y}}\right]^{2}+\frac{2}{\sigma_{y}^{2}}\left(r+\eta+\lambda \sigma_{x} \rho_{x}-\mu_{x}\right)}<0 .
$$

Proof. See Appendix A.

The stock price in Proposition 3 is the expected present value of the future cash flow stream $X_{t}$ under the risk-neutral measure. The cash flow stream $X_{t}$ follows a GBM whose parameters may undergo a negative regime change. The regime change occurs either the first time another process $Y_{t}$ (which is correlated with $X_{t}$ ) hits a lower boundary $\bar{Y}$, or when an idiosyncratic Poisson jump occurs. This problem set-up and solution, to the best of my knowledge, is new to the Finance literature and therefore constitutes an independent technical contribution of this paper. ${ }^{6}$

It is important to note that, in the absence of a purely idiosyncratic jump to hostile renegotiation (whose occurrence is governed by a Poisson process with parameter $\eta$ ), there are no jumps in asset prices in my framework. Accordingly, Equations (2), (5) and (4) show that emerging market sovereign bond and stock prices are smooth functions of fundamentals $Y_{t}, X_{t}$ and $\Lambda_{t}$, which follow a diffusion process without jumps. Therefore, there is no jump risk premium in the model: the systematic risk of bonds and stocks is determined by their (continuous) covariance with the global pricing kernel. This is in line with most of the structural models of corporate bond and equity pricing (e.g. Galai and Masulis, 1976; Leland, 1994; Bakshi and Chen, 2005).

Note also that Equation (5) does not depend on sovereign rulers' time preference $\delta$, or on the gross endowment trend after hostile renegotiation $\overline{\mu_{y}}$. This is good news for valuation: such parameters are hard to specify, but all relevant information about them is embedded in the average sovereign yield spread $S_{t}$, which is observable in practice. Proposition 4 below defines the useful concept of Value Discount.

Proposition 4. The emerging market stock is priced at a discount relative to an otherwise identical stock not subjected to country risk. The value discount $V D_{t}=\left|\left(P_{t} / P_{t}^{\text {no risk }}\right)-1\right|$ increases with the average sovereign spread $S_{t}$ and is given by

$$
V D_{t}\left(S_{t}\right)=\frac{\left[\mu_{x}-\overline{\mu_{x}}+\lambda \rho_{x}\left(\overline{\sigma_{x}}-\sigma_{x}\right)\right]\left[\eta+\left(r+\lambda \rho_{x} \sigma_{x}-\mu_{x}\right)\left(\frac{S_{t}\left(\frac{1+\frac{\eta}{r+m} \bar{c} \frac{\bar{c}}{c}}{1-\frac{\bar{c}}{c}}\right)^{-\eta}}{S_{t}+r+m}\right)^{\frac{\alpha}{\beta}}\right]}{\left(r+\eta+\lambda \rho_{x} \sigma_{x}-\mu_{x}\right)\left(r+\lambda \rho_{x} \overline{\sigma_{x}}-\overline{\mu_{x}}\right)} .
$$

Proof. See Appendix A.

Emerging market stocks are priced at a discount because of country risk. When the sovereign spread is high, a negative macroeconomic regime change is more likely and therefore stock prices are lower.

${ }^{6}$ See Eq. (14) in Appendix A for the formula relating $P_{t}$ to $Y_{t} / \bar{Y}$ explicitly. 


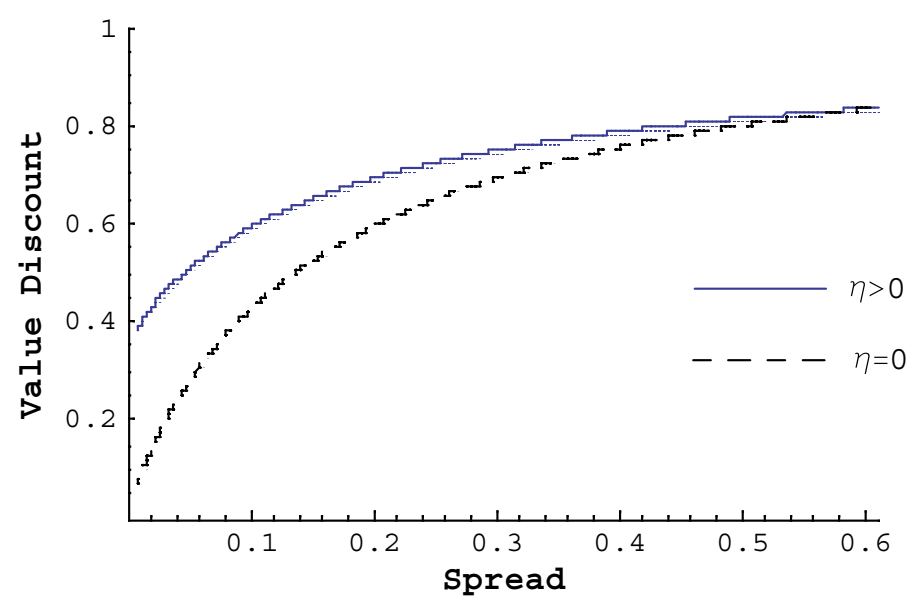

Fig. 1. Value discount and sovereign yield spread with (solid) and without (dashed) exogenous jump to default $\left(\operatorname{VD}\left(S_{t}\right)\right)$.

Note that the discount $V D_{t}\left(S_{t}\right)$ depends on $\lambda \rho_{x}$ and $\lambda \rho_{y}$ : the discount depends not only on the likelihood of a negative regime change, but also on global risk aversion. Also note that the Value Discount varies from stock to stock within the emerging market, since it depends on the stock-specific parameters $\mu_{x}$, $\overline{\mu_{x}}, \rho_{x}, \rho_{x y}, \sigma_{x}$ and $\overline{\sigma_{x}}$. Therefore, the typical industry practice of not discriminating the impact of country risk among stocks in a given emerging market is not supported by the model. ${ }^{7}$ Fig. 1 plots $V D_{t}\left(S_{t}\right)$ with the parameters in Table 3. To illustrate the effect of the exogenous jump to hostile renegotiation, Fig. 1 also displays the no-jump case $\eta=0$.

Proposition 5 below calculates instantaneous second moments of stock returns, and states their relationship to sovereign yield spreads. The main reason I derive model implications regarding second moments of returns is because these can be empirically measured more accurately than expected returns - see Merton (1976). I explore this feature in the model calibration in Section 3.3.

Proposition 5. The instantaneous stock return volatility $\sigma_{P}$, bond return volatility $\sigma_{B}$, and stock-bond covariance $\sigma_{P B}$ are analytical functions of the average sovereign yield spread $S_{t}$. The functions are in Appendix A. The covariance $\sigma_{P B}$ is always positive. Conditioned on the absence of a jump to hostile renegotiation, $\sigma_{B}, \sigma_{B}$ and the correlation coefficient between bond and stock returns increase with the sovereign yield spread.

Proof. See Appendix A.

Conditioned on the absence of a jump to hostile renegotiation, stock return volatility increases with the sovereign spread. This is because endowment growth shocks are i.i.d. over time, and the effect of a given endowment growth shock on the probability of hostile renegotiation is higher when the economy is closer to renegotiation boundary $\bar{Y}$. When the economy is far from the boundary, a shock barely changes the probability of reaching the boundary. On the other hand, a shock of the same magnitude has a major effect on the probability if the economy is already close to the boundary. ${ }^{8}$ I study second moments conditional on the absence of a jump to hostile renegotiation because those can be measured with daily return data.

Figs. 2-4 below confirm that $\sigma_{P}$ and $\rho_{P B}$ increase with the sovereign spread, and show that the volatility ratio $\sigma_{B} / \sigma_{P}$ increases on the sovereign spread except for extremely high spread levels. The figures are plotted with the parameters in Table 3 and also display the no-jump case $\eta=0$.

\footnotetext{
7 Damodaran (2003) proposes a clever (but ad hoc) way to adjust the typical industry method to account for different exposures to country risk within the same emerging market.

8 The following thought experiment is useful for intuition. Flip a coin 10 times and before each flip compute the probability of getting Heads in all flips. Note that this probability goes up faster as successes accumulate. After the 8th success, right before the 9th flip, the probability is 0.25 . After the 9th success, the probability is 0.50 , and after the 10 th success the probability is 1.00 . The probability of getting Heads ten times goes up by 0.25 after the 9 th success, and by 0.50 after the 10 th success.
} 


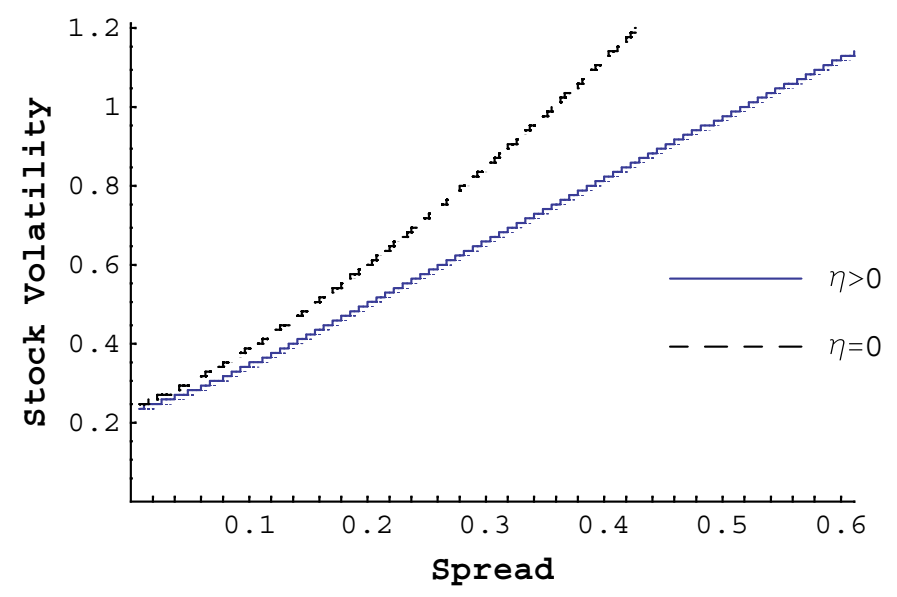

Fig. 2. Stock return volatility and sovereign yield spread with (solid) and without (dashed) exogenous jump to default $\left(\sigma_{P}\left(S_{t}\right)\right)$.

Fig. 2 shows that emerging market stocks display "excess volatility" relative to earnings. In the absence of country risk, Equation (16) in Appendix A shows that the volatility of stock returns would be equal to the volatility of earnings/dividends, which is $\sigma_{x}=0.236$ in my calibration (Table 3). After the hostile renegotiation of foreign debt, the volatility of returns is also equal to volatility of earnings, which is $\overline{\sigma_{x}}=$ 0.355 (Table 3). Fig. 2 shows that the stock return volatility can be much higher than 0.236 and 0.355 .

The model provides a formula of the instantaneous minimum variance hedge ratio between emerging market stocks and sovereign bonds $\left(\rho_{P B}\left(\sigma_{P} / \sigma_{B}\right)\right)$. The price of an emerging market stock is positively correlated with the price of the emerging market sovereign bond because both are affected by the same macroeconomic regime change. However, these securities are not perfectly correlated because the stock price depends on earnings $X_{t}$ (see Eq. (5)) whereas bond prices do not (see Eq. (2)). Fig. 5 shows that the hedge ratio (conditioned on the absence of a jump to hostile renegotiation) is typically decreasing in the sovereign spread.

Proposition 6 below shows that country risk is priced: emerging market expected stock returns increase with the sovereign yield spread.

Proposition 6. The instantaneous expected return of the emerging market stock is

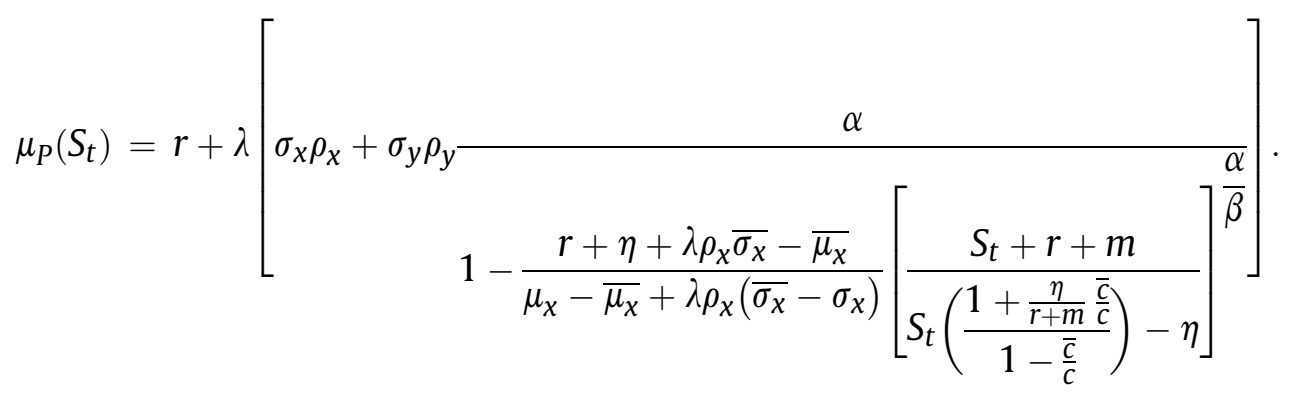

The expected return is always larger than the risk-free rate and increases with the average sovereign spread $S_{t}$.

Proof. See Appendix A.

Note that the expected excess return has two terms. The first term $\lambda \sigma_{x} \rho_{x}$ is the compensation for positive cash flow correlation with the global pricing kernel. This term is constant. The second term is the compensation associated with the endogenous component of country risk. ${ }^{9}$ Since $\rho_{y}>0$, the negative regime change in the emerging country tends to occur in bad states of the global economy, and therefore country risk is priced. The compensation for country risk increases with the sovereign spread because there is more systematic risk at higher spread levels. This is because the volatility of returns increases when the country is closer to the hostile renegotiation boundary, whereas the instantaneous fundamental

\footnotetext{
${ }^{9}$ Note that the second term vanishes if the stock's cash flow process remains the same following the hostile renegotiation of foreign debt $\left(\mu_{x}=\overline{\mu_{x}}\right.$ and $\left.\sigma_{x}=\overline{\sigma_{x}}\right)$.
} 


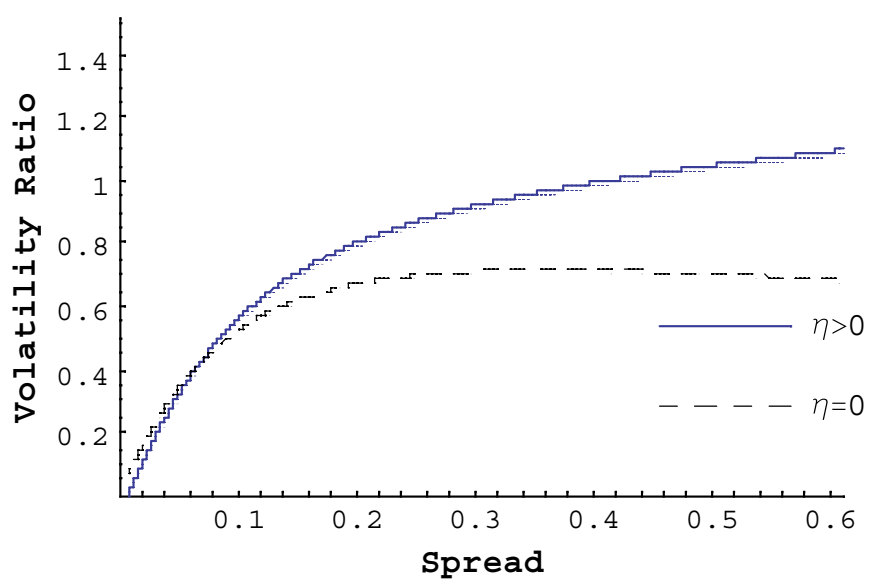

Fig. 3. Ratio of sovereign bond return volatility and stock return volatility and sovereign yield spread with (solid) and without (dashed) exogenous jump to default $\left(\left(\sigma_{B} / \sigma_{P}\right)\left(S_{t}\right)\right)$.

correlations $\rho_{y}, \rho_{x}$ and $\rho_{x y}$ remain constant. So, the beta of an emerging market stock with respect to the true pricing kernel is higher at higher spread levels. Fig. 6 plots the expected return function with the parameters in Table 3, and shows that the variation in expected returns is economically large. ${ }^{10}$

Industry practice uses yield spreads on sovereign bonds to "adjust" the World CAPM in order to value emerging market assets (Estrada, 2007). However, such adjustments are arbitrary. Proposition 6 could provide quantitative guidance on the determination of emerging markets' expected returns based on information contained in sovereign spreads. It turns out that the model's quantitative implications are different from the typical industry practice. First, as noted previously, different stocks in an emerging market are affected differently by country risk - the formula for $\mu_{P}$ depends on stock-specific parameters. Moreover, in contrast to the typical industry practice, the expected stock return does not increase one for one with the sovereign spread. In particular, $\mu_{P}$ is concave in $S_{t}$. Therefore, the typical industry practice for valuing emerging market stocks "underreacts" to spread changes at low spread levels, and "overreacts" to spread changes at high spread levels. Future research may investigate whether a properly hedged relative trading strategy that exploits these systematic patterns yields abnormally high returns.

\section{Empirical analysis}

In this section I evaluate some of the model's predictions. In Section 3.2 I use regression analysis to evaluate qualitative predictions of the model. I use data from the largest emerging markets that have ever been part of J.P. Morgan's Emerging Markets Bond Index Plus (EMBI+), my source of bond market data. In Section 3.3 I evaluate the model's quantitative predictions by calibrating it to Brazil's Stock Market Index. Brazil is a natural choice because it is the largest emerging market that has been part the EMBI+ Index. I show that the model can match important features of Brazil's data with reasonable parameters. I start by describing the data.

\subsection{Data}

I use sovereign bond and stock market data of nine countries. My sample runs from January 1, 1998 to December 31, 2007. Bond market data are from J.P. Morgan's EMBI+ Index. Index levels and sovereign spreads were not available before January 1998. The EMBI+ Index represents a valueweighted portfolio of liquid US dollar denominated sovereign bonds traded internationally. Percent changes in Index levels are US dollar returns on the sovereign bond portfolio. Yield spreads of individual bonds are computed relative to the US Treasury yield curve. Index sovereign spreads are valueweighted spreads of the individual bonds in the portfolio. In terms of stock market capitalization at the

\footnotetext{
10 In my model, country risk affects stock prices through the nominator (reducing expected future cash flows) and through the denominator (increasing expected returns). Fig. 6 shows only the effect of country risk on the denominator.
} 


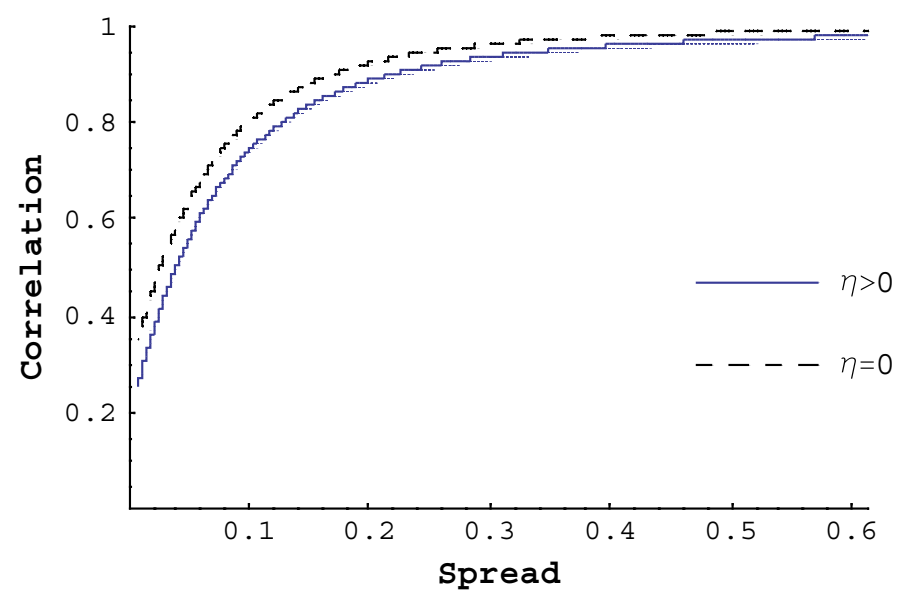

Fig. 4. Correlation of returns of stock and sovereign bond and sovereign yield spread with (solid) and without (dashed) exogenous jump to default $\left(\rho_{P B}\left(S_{t}\right)\right)$.

end of 2007, the largest countries that have ever been part of the EMBI+ Index are Brazil, South Korea, Russia, South Africa, Mexico, Malaysia, Turkey, Poland, and Argentina. Not all these countries were part of the Index during January 1998-December 2007 - the sample periods for each country are in Table A.1. I use the MSCI Index to compute US dollar daily stock returns in the local stock markets of the countries in my sample.

Daily returns on the EMBI+ Index are calculated using daily New York close prices. Therefore, I need to control for the fact that stocks markets in Europe, Africa and Asia are closed during most of New York's trading time when calculating daily correlations of bond and stock market returns. I follow Forbes and Rigobon (2002) and use rolling averages of two-day returns to compute such correlations. Table 1 presents summary statistics of the financial data grouped by calendar month.

Table 1 shows that average stock returns are measured much less accurately than second moments of returns. For all countries, the Annual Stock Return is the only variable in the table whose standard deviation is higher than the average. Furthermore, this simple comparison underestimates the uncertainty of average returns. This is because, in contrast to the other variables in Table 1, the Annual Stock Return is calculated using overlapping data (monthly 12-month returns).

\subsection{Regressions}

I check model implications regarding how second moments of bond and stock returns relate to sovereign yield spread levels. I focus on implications for second moments of returns because, in

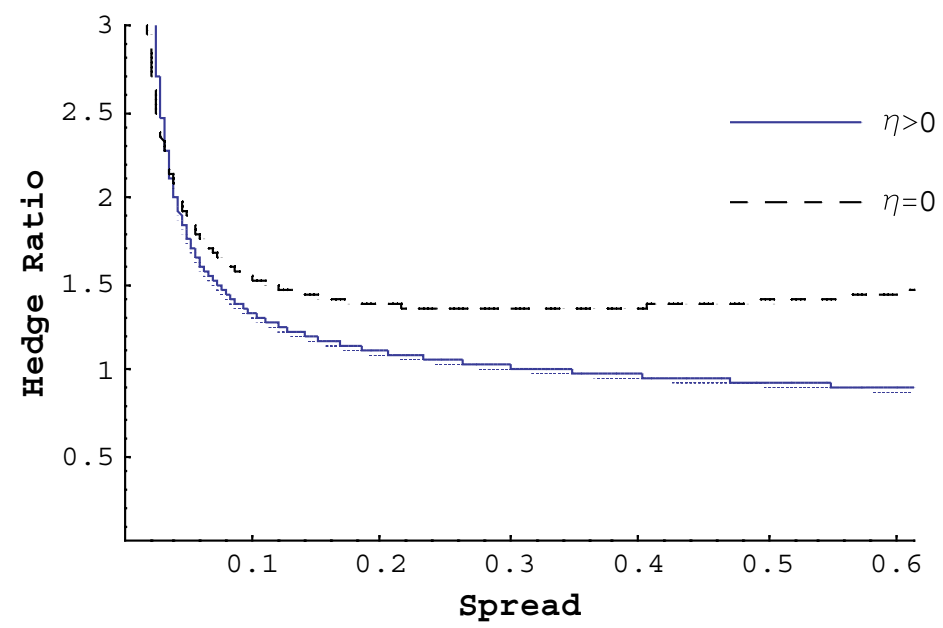

Fig. 5. Minimum variance hedge ratio between stock and sovereign bonds and sovereign yield spread with (solid) and without (dashed) exogenous jump to default $\left(\rho_{P B}\left(S_{t}\right)\left(\sigma_{B} / \sigma_{P}\right)\left(S_{t}\right)\right)$. 


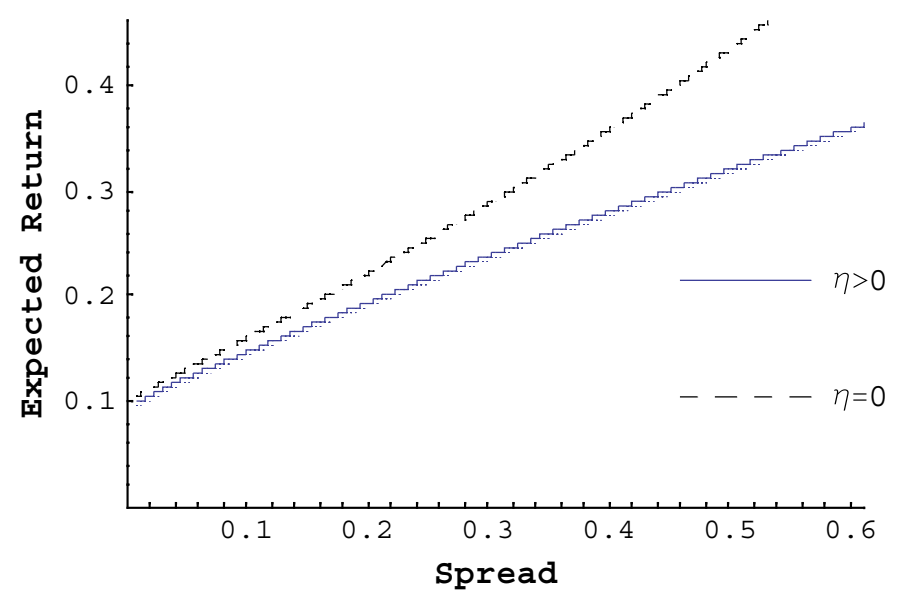

Fig. 6. Expected return on stock and sovereign yield spread with (solid) and without (dashed) exogenous jump to default $\left(\mu_{P}\left(S_{t}\right)\right)$.

contrast to expected returns, they can be more accurately estimated with finer data sampling (Merton, 1976). Table 2 below reports results of regressions with non-overlapping monthly data based on daily stock and bond returns.

Table 2 shows that most regressions confirm model predictions in Proposition 5. First, in 8 out of 9 countries stock volatility is positively related to the sovereign spread level. Results are statistically significant at $1 \%$ for 7 of the 8 countries, with the exception of Malaysia, which has only 34 monthly observations. The results are economically significant. For example, a one standard deviation increase in the spread increases stock volatility by $18 \%$ in Brazil, $16 \%$ in South Korea and 39\% in Russia. Second, in 8 of 9 countries sovereign bonds become more volatile relative to stocks as the sovereign spread increases. Again, results are statistically at $1 \%$ for 7 of the 8 countries, with the exception of smallsample Malaysia. Third, regressions show that for 6 of the 9 countries the correlation between sovereign bond returns and stock returns increases with the sovereign spread. Note that the 3 countries for which the correlation of daily returns does not increase in the spread are located in Africa, Asia and Europe. For these countries daily correlations are measured with less precision due to the time zone problem. Finally, note that all three model predictions I tested are confirmed in Brazil, South Korea, Russia, the 3 largest markets under study.

Ideally, I would want to test Proposition 6 of Section 2.1, which states that expected returns on emerging market stocks increase with the sovereign yield spread. However, my data only cover ten years of data and therefore is too small to allow inference about stock return probability. Nonetheless, previous research by Erb et al. (1995, 1996a,b) and Gendreau and Heckman (2003) suggests that expected returns indeed increase with the sovereign spread, as my model predicts. ${ }^{11}$

\subsection{Model calibration and quantitative implications}

I calibrate the model to Brazil's Stock Market Index. My calibration strategy is to fix some parameters based on external information, and choose the remaining ones in order to match features of the Brazilian data. I fix the parameters that can be either observed directly or estimated with reasonable accuracy. I match second moments of returns in Brazil's financial data, which can be measured accurately with daily sampling. I verify that the entire parameter set implies a reasonable expected stock return, and that the parameters that are not pre-determined are within the range encountered in the literature. Based on these verifications, I conclude that the model can match the data with reasonable parameter choices. Table 3 Panel A summarizes model parameters. In the paragraphs below I start by

\footnotetext{
11 Erb et al. (1995, 1996a,b) use either Institutional Investors' country ratings or ICRG's country ratings. These alternative measures of "country risk" are correlated with sovereign yield spreads. Erb et al. (1998) document a 0.81 correlation between Institutional Investors' country ratings and sovereign yield spreads (see also Scholtens, 1999). Harvey (2006) reports that the correlation of ICRG's Composite Rating and (log) sovereign yield spreads is $\sqrt{0.4451}=0.6672$.
} 
Table 1

Summary statistics of financial data.

\begin{tabular}{llllllllll}
\hline & Brazil & S. Korea & Russia & S. Africa & Mexico & Malaysia & Turkey & Poland & Argentina \\
\hline Sovereign Spread & 0.0702 & 0.0236 & 0.1027 & 0.0129 & 0.0306 & 0.0118 & 0.0480 & 0.0156 & 0.0632 \\
& $(0.042)$ & $(0.015)$ & $(0.145)$ & $(0.006)$ & $(0.019)$ & $(0.004)$ & $(0.026)$ & $(0.009)$ & $(0.040)$ \\
Annual Stock Return & 0.204 & 0.384 & 0.314 & 0.262 & 0.197 & 0.127 & 0.335 & 0.122 & 0.149 \\
& $(0.467)$ & $(0.459)$ & $(0.600)$ & $(0.185)$ & $(0.280)$ & $(0.154)$ & $(0.651)$ & $(0.285)$ & $(0.408)$ \\
Stock volatility & 0.335 & 0.459 & 0.419 & 0.344 & 0.259 & 0.125 & 0.476 & 0.289 & 0.317 \\
& $(0.150)$ & $(0.126)$ & $(0.263)$ & $(0.161)$ & $(0.113)$ & $(0.327)$ & $(0.237)$ & $(0.104)$ & $(0.141)$ \\
Ratio of bond-stock volatilities & 0.406 & 0.184 & 0.359 & 0.199 & 0.270 & 0.527 & 0.193 & 0.336 & 0.569 \\
& $(0.206)$ & $(0.137)$ & $(0.263)$ & $(0.103)$ & $(0.126)$ & $(0.236)$ & $(0.105)$ & $(0.170)$ & $(0.348)$ \\
Bond-stock correlation & 0.582 & 0.175 & 0.312 & 0.018 & 0.281 & -0.075 & 0.540 & 0.080 & 0.513 \\
& $(0.174)$ & $(0.323)$ & $(0.282)$ & $(0.327)$ & $(0.276)$ & $(0.276)$ & $(0.291)$ & $(0.327)$ & $(0.225)$ \\
Sample size & 120 & 51 & 120 & 68 & 120 & 34 & 101 & 112 & 77 \\
\hline
\end{tabular}

This table has averages and standard deviations of monthly data. The sovereign yield spread is from J.P. Morgan's EMBI+ Index. Stock returns are US dollar returns on the MSCI Index. Bond returns are US dollar returns on the EMBI+ Index. Sovereign Spread is the average yield spread in each calendar month. Annual Stock Return is the cumulative return on the MSCI Index in the previous 12 months. Bond and stock volatilities are the square root of the sum of squared daily returns within each calendar month, annualized by multiplying by $\sqrt{12}$. Bond-stock correlation is the correlation of daily stock and bond returns within each calendar month. The full sample periods is January 1998-December 2007, and a country's sample period is determined by existence of EMBI+ Index data. Countries are ordered by market capitalization at the end of 2007.

describing the pre-determined parameters. Then, I explain how to choose the remaining parameters in order to match second moments of securities' returns.

\subsubsection{Pre-determined parameters}

The nominal risk-free interest rate and the maximum Sharpe Ratio are respectively $r=0.0547$ and $\lambda=0.70$, equal to the long-run averages in Brennan et al. (2004). These authors set the long-run real

Table 2

Regressions.

\begin{tabular}{|c|c|c|c|c|c|c|c|c|c|}
\hline & Brazil & S. Korea & Russia & S. Africa & Mexico & Malaysia & Turkey & Poland & Argentina \\
\hline \multicolumn{10}{|c|}{ Panel A: Log of stock volatility } \\
\hline Constant & $\begin{array}{l}-1.446 \\
(-20.07)\end{array}$ & $\begin{array}{l}-1.057 \\
(-13.25)\end{array}$ & $\begin{array}{l}-1.258 \\
(-22.34)\end{array}$ & $\begin{array}{l}-1.431 \\
(-15.61)\end{array}$ & $\begin{array}{l}-1.771 \\
(-25.36)\end{array}$ & $\begin{array}{l}-2.275 \\
(-16.50)\end{array}$ & $\begin{array}{l}-1.268 \\
(-14.43)\end{array}$ & $\begin{array}{l}-1.548 \\
(-24.41)\end{array}$ & $\begin{array}{l}-1.490 \\
(-19.36)\end{array}$ \\
\hline Sovereign spread & $\begin{array}{l}3.997 \\
(4.15)\end{array}$ & $\begin{array}{l}10.010 \\
(3.50)\end{array}$ & $\begin{array}{l}2.273 \\
(7.37)\end{array}$ & $\begin{array}{l}-4.890 \\
(-0.74)\end{array}$ & $\begin{array}{l}11.283 \\
(5.77)\end{array}$ & $\begin{array}{l}13.60 \\
(1.28)\end{array}$ & $\begin{array}{l}8.964 \\
(4.89)\end{array}$ & $\begin{array}{l}16.18 \\
(4.09)\end{array}$ & $\begin{array}{l}4.152 \\
(3.47)\end{array}$ \\
\hline$R^{2}$ & 0.207 & 0.267 & 0.364 & 0.01 & 0.308 & 0.038 & 0.303 & 0.203 & 0.185 \\
\hline Sample size & 120 & 50 & 51 & 68 & 120 & 34 & 101 & 112 & 77 \\
\hline \multicolumn{10}{|c|}{ Panel B: Log of ratio of bond-stock volatilities } \\
\hline Constant & $\begin{array}{l}-1.736 \\
(-17.28)\end{array}$ & $\begin{array}{l}-2.483 \\
(-24.01)\end{array}$ & $\begin{array}{l}-1.548 \\
(-22.01)\end{array}$ & $\begin{array}{l}-2.401 \\
(-15.18)\end{array}$ & $\begin{array}{l}-1.667 \\
(-16.42)\end{array}$ & $\begin{array}{l}-0.967 \\
(-5.29)\end{array}$ & $\begin{array}{l}-2.236 \\
(-25.90)\end{array}$ & $\begin{array}{l}-1.610 \\
(-11.61)\end{array}$ & $\begin{array}{l}-0.978 \\
(-8.19)\end{array}$ \\
\hline Sovereign spread & $\begin{array}{l}9.780 \\
(8.25)\end{array}$ & $\begin{array}{l}25.992 \\
(8.20)\end{array}$ & $\begin{array}{l}3.025 \\
(9.72)\end{array}$ & $\begin{array}{l}49.66 \\
(3.97)\end{array}$ & $\begin{array}{l}8.275 \\
(3.85)\end{array}$ & $\begin{array}{l}21.641 \\
(1.54)\end{array}$ & $\begin{array}{l}12.217 \\
(7.58)\end{array}$ & $\begin{array}{l}-9.998 \\
(-1.38)\end{array}$ & $\begin{array}{l}4.053 \\
(2.68)\end{array}$ \\
\hline$R^{2}$ & 0.538 & 0.520 & 0.449 & 0.267 & 0.109 & 0.056 & 0.392 & 0.029 & 0.082 \\
\hline Sample size & 120 & 50 & 120 & 68 & 120 & 34 & 101 & 112 & 77 \\
\hline \multicolumn{10}{|c|}{ Panel C: Fisher transformation of correlation of bond-stock returns } \\
\hline Constant & $\begin{array}{l}0.570 \\
(11.71)\end{array}$ & $\begin{array}{l}-0.021 \\
(-0.21)\end{array}$ & $\begin{array}{l}0.301 \\
(7.35)\end{array}$ & $\begin{array}{l}0.236 \\
(1.86)\end{array}$ & $\begin{array}{l}0.114 \\
(2.27)\end{array}$ & $\begin{array}{l}0.067 \\
(0.48)\end{array}$ & $\begin{array}{l}0.773 \\
(8.94)\end{array}$ & $\begin{array}{l}-0.116 \\
(-1.80)\end{array}$ & $\begin{array}{l}0.410 \\
(8.80)\end{array}$ \\
\hline Sovereign spread & $\begin{array}{l}1.957 \\
(3.12)\end{array}$ & $\begin{array}{l}9.125 \\
(2.56)\end{array}$ & $\begin{array}{l}0.494 \\
(3.03)\end{array}$ & $\begin{array}{l}-17.060 \\
(-1.94)\end{array}$ & $\begin{array}{l}5.456 \\
(4.54)\end{array}$ & $\begin{array}{l}-12.423 \\
(-1.31)\end{array}$ & $\begin{array}{l}-1.691 \\
(-0.96)\end{array}$ & $\begin{array}{l}13.256 \\
(3.45)\end{array}$ & $\begin{array}{l}1.639 \\
(2.62)\end{array}$ \\
\hline$R^{2}$ & 0.088 & 0.136 & 0.047 & 0.069 & 0.137 & 0.026 & 0.010 & 0.109 & 0.084 \\
\hline Sample size & 120 & 50 & 120 & 68 & 120 & 34 & 101 & 112 & 77 \\
\hline
\end{tabular}

This table contains results of OLS regressions of dependent variables on the corresponding sovereign yield spread with monthly data. Sovereign spread is the average EMBI+ yield spread in each calendar month. Stock returns are daily US dollar returns on the corresponding MSCI Index. Bond returns are daily US dollar returns on the corresponding EMBI+ Index. Bond and stock volatilities are the square root of the sum of squared daily returns within each calendar month, annualized by multiplying by $\sqrt{12}$. Bond-stock correlation is the correlation of daily stock and bond returns within each calendar month. The full sample period is January 1998-December 2007, and a country's sample period is determined by existence of EMBI+ Index data. Countries are ordered by market capitalization at the end of 2007. $t$-stats calculated with Newey-West standard errors are in parentheses. 
Table 3

Model calibration.

\begin{tabular}{lll}
\hline Panel A: Parameters & & 0.0547 \\
$r$ & Interest rate & 0.70 \\
$\lambda$ & Maximum Sharpe Ratio & 0.008 \\
$\mu_{y}$ & Endowment growth trend & 0.024 \\
$\sigma_{y}$ & Endowment growth volatility & 0.236 \\
$\sigma_{x}$ & Dividend growth volatility & 0.25 \\
$\bar{c} / c$ & Sovereign debt recovery value & 6.69 \\
$1 / m$ & Sovereign debt average maturity & 0.0120 \\
$\eta$ & Probability of jump to hostile renegotiation & 0.085 \\
$\mu_{x}$ & Dividend growth trend & 0.041 \\
$\overline{\mu_{x}}$ & Dividend growth trend after hostile renegotiation \\
$\overline{\sigma_{x}}$ & Dividend growth volatility after hostile renegotiation & 0.355 \\
$\rho_{y}$ & Correlation between endowment growth and pricing kernel innovations & 0.358 \\
$\rho_{x}$ & Correlation between dividend growth and pricing kernel innovations & 0.261 \\
$\rho_{x y}$ & Correlation between dividend growth and endowment growth & 0.250 \\
\hline
\end{tabular}

\begin{tabular}{lll}
\hline & Brazilian data (medians) & Model (at $S_{t}=0.0623$ ) \\
\hline Panel B: Data and model values & 0.0688 & - \\
Sovereign spread & 0.0623 & 0.0623 \\
Liquidity-adjusted sovereign spread & 0.291 & 0.291 \\
Stock return volatility & 0.386 & 0.386 \\
Ratio of bond-stock volatilities & 0.619 & 0.619 \\
Correlation of bond-stock returns & 0.229 & 0.154 \\
Annual stock return & - & 0.541 \\
Value discount & 120 & - \\
Sample size & 120 & - \\
\hline
\end{tabular}

Panel A presents model parameters used to plot Figs. 1-6 and compute the model values in Panel B. The model is calibrated to Brazil's Stock Market Index, as discussed in Section 3.3. The time unit is one year. The first row in Panel B presents medians of Brazil's financial data. The second row presents corresponding model-implied values, when the model is evaluated with the parameters in Panel A and at the median Brazilian sovereign spread. The liquidity adjustment to the spread is from Longstaff et al. (2005). The spread is from J.P. Morgan's EMBI+ Index for Brazil. Stock returns are US dollar returns on Brazil's MSCI Stock Index. Bond returns are US dollar returns on Brazil's EMBI+ Index. Bond and stock volatilities are the square root of the sum of squared daily returns in the calendar month and annualized by multiplying by $\sqrt{12}$. The correlation of bond and stock returns is calculated from daily data within each calendar month. In each calendar month, Annual Stock Return is the cumulative 12-month return. Medians are calculated across the 120 months of January 1998-December 2007.

interest rate to 0.0162 and the long-run inflation to 0.0385 , which adds up to 0.0547 . I use nominal interest rates because the sovereign yield spread is read from nominal bonds.

The endowment growth trend and volatility are respectively $\mu_{y}=0.008$ and $\sigma_{y}=0.024$, equal to Brazil's average and standard deviation of the real growth in per capita GDP from 1987 to 2007. These numbers are calculated from the annual time series of Brazil's GDP per capita (at constant prices and local currency) available at the IMF's World Economic Outlook Database. I use real rather than nominal rates because sovereign rulers exercise their option to promote a hostile renegotiation of foreign debt when real (rather than nominal) GDP per capita reaches some lower boundary. The use of real GDP here is not inconsistent with my use of nominal interest rates because $\mu_{y}$ and $\sigma_{y}$ only matter for the timing of the regime change, and do not affect cash flows directly. ${ }^{12}$ Recall from Section 2.1 that, when the purpose is to price stocks based on information embedded in the sovereign yield spread, I don't need to specify either $\delta$ or $\overline{\mu_{y}}$.

After the hostile renegotiation, the recovery value of sovereign debt as a fraction of face value is $(\bar{c} / c)=0.25$. This is equal to the recovery value in Argentina's hostile negotiation of its foreign debt (Sturzenegger and Zettelmeyer, 2007). The average maturity of sovereign debt is $(1 / \mathrm{m})=6.69$, equal to the average maturity of Brazil's sovereign bonds from January 1998 to June 2007.13

\footnotetext{
12 Bond prices are present values of nominally fixed dollar amounts, and stock prices are present values of nominal dividends.

13 From January 1998 to June 2007, the average maturity of Brazilian sovereign debt ranged from 5.63 years (2003:Q2) to 8.37 years (2006:Q2). This time series is on the Brazilian central bank's website: http://www4.bcb.gov.br/?TIMESERIESSEARCH.
} 
I infer the volatility of earnings $\sigma_{x}$ from my regression analysis in Section 3.2. In my model the volatility of stock returns is equal to the volatility of earnings when the sovereign spread is zero (see Eq. (17) and Fig. 2). Table 2 Panel A shows that the intercept of the regression of the log of Brazil's stock volatility on Brazil's sovereign spread is -1.446 ( $t$-stat -20.07 ). Therefore, I set $\sigma_{x}=e^{-1.446}=0.236$ per year. One alternative would be to use the realized volatility of earnings in the sample period. However, financial managers have incentives to smooth out earnings, rendering difficult for one to infer the true $\sigma_{x}$ from realized earnings. This concern is especially valid in emerging markets (Leuz et al., 2003). Furthermore, it is not clear how to treat shifting exchange rate regimes empirically. When the local currency is pegged to the US dollar, realized dollar denominated earnings will be substantially less volatile than when the currency is allowed to float.

The instantaneous jump probability is $\eta=0.011$ : on average, an exogenous jump to hostile renegotiation happens once each 90 years. This is the largest $\eta$ still consistent with historically observed sovereign yield spreads for Brazil. When $\eta=0.011$, given my aforementioned choices for $r, 1 / \mathrm{m}$ and $\bar{c} / \mathrm{c}$, the minimum sovereign spread in the model is 0.0081 . Sovereign spreads in the data are calculated relative to the US Treasury yield curve, thus I add the US Treasury liquidity premium to my modelimplied spread before comparing it to the data. Longstaff et al. (2005) report an average US Treasury liquidity premium of 0.0065 . Therefore, the minimum liquidity-adjusted spread in the model is $0.0081+0.0065=0.0146$, which is equal to the lowest historical spread ever achieved by Brazil's EMBI+ Index (in June 2007).

\subsubsection{Free parameters}

The remaining 6 parameters of the model cannot be easily estimated from data. My calibration strategy is to choose them in order to match second moments of securities' returns, measured with daily data. To make matters simple, I evaluate the model at the median sovereign yield spread in the sample period, and match model-implied second moments to the corresponding median second moments in the sample period (Table 3 Panel B). ${ }^{14}$ I evaluate the model at $S_{t}=0.0688-0.0065=0.0623$, where 0.0688 is the median Brazilian EMBI+ sovereign yield spread in the sample period, and 0.0065 is the average US Treasury liquidity premium reported by Longstaff et al. (2005). The target second moments are the median stock return volatility $\sigma_{P}=0.291$, the median ratio of volatilities of sovereign bond returns and stock returns $\sigma_{B} / \sigma_{P}=0.386$, and the median correlation between sovereign bond and stock returns $\rho_{P B}=0.619$.

I claim that model can match the three aforementioned second moments of securities' returns with reasonable parameters for $X_{t}$. First, the parameter set implies a reasonable expected stock return $\mu_{P}=0.128$ and risk premium $\mu_{P}-r=0.0733$ when the sovereign spread is $S_{t}=0.0636$. Second, in the paragraphs that follow I argue that the parameters that result from my matching procedure are within the range encountered in the literature.

The correlation between endowment growth and pricing kernel innovations is $\rho_{y}=0.358$. Consumption-based models with frictionless markets imply that a country's endowment growth is perfectly negatively correlated with the global pricing kernel. However, it is well known that market frictions prevent full international risk sharing (Backus et al., 1992), especially in the case of emerging economies with the option of defaulting on their foreign debts (Kehoe and Perri, 2002).

The nominal growth trend of Brazil's Stock Market Index earnings is $\mu_{x}=0.0855$, a little higher than the trend of US aggregate earnings estimated by Bhamra et al. (2007). These authors estimate that the real growth trend of US aggregate earnings from 1947 to 2005 is 0.0343 , which results in a nominal growth rate of 0.0728 after adding the 0.0385 long-term inflation rate in Brennan et al. (2004). After the hostile renegotiation of foreign debt and associated regime change, the nominal growth trend drops to $\overline{\mu_{x}}=0.0410$. Similarly, after the hostile renegotiation of foreign debt and associated regime change, the Index's nominal growth volatility increases to $\overline{\sigma_{x}}=0.38$. Both the pre-change and the post-change volatilities $\sigma_{x}$ and $\bar{\sigma}_{x}$ are within the range of values encountered in the literature. Working with US data, Bhamra et al. (2007) set the long-term volatility of aggregate earnings real growth to 0.10. For

\footnotetext{
${ }^{14}$ I believe that, in order to match the realized dynamic relationship between sovereign spreads and stock returns, the model must allow time variation in $\eta$, the exogenous probability of jump to default/renegotiation. This is left for future research.
} 
individual US firms, Bhamra et al. (2007) adopt a long-term volatility of 0.42 , which compares to Chen's (2007) choices of 0.20 for a typical US Aaa-rated firm and 0.35 for a typical US Baa-rated firm.

The correlation between earnings growth and pricing kernel innovations is $\rho_{x}=0.261$, and the correlation between earnings growth and endowment growth is $\rho_{x y}=0.250$. These choices are within the range encountered in the literature. Longstaff and Piazzesi (2004) estimate that the correlation between US earnings growth and US consumption growth from 1929 to 2001 is 0.687 . In contrast, Bhamra et al. (2007) calibrate the correlation between US earnings growth and US consumption growth to 0.1998.

The model, calibrated with the parameters in Table 1, implies that the discount at which the Brazilian stock market trade vis-à-vis markets not subject to country risk is $V D=0.541$, when the (liquidity-adjusted) sovereign spread is at its median 1998-2007 level (0.0623).

\section{Conclusion}

I price emerging market stocks based on a measure of country risk. This idea is not new: it has dominated industry practice for the last 15 years (Mariscal and Lee, 1993; Keck et al., 1998; Estrada, 2007), and appears in empirical research by Bekaert (1995), Erb et al. (1995, 1996a,b), Bailey and Chung (1995), Bansal and Dahlquist (2002), and Damodaran (2003). However, to the best of my knowledge, I provide the first model with formulas for emerging market stock $\mathrm{P} / \mathrm{E}$ ratios and expected returns as functions of yield spreads on sovereign bonds (the most popular measure of country risk). These formulas are available in analytical form. In the model, the price of an emerging market stock is the appropriately discounted present value of a stochastically growing perpetuity whose trend and volatility may undergo a regime change. This regime change can be either endogenous, when sovereign rulers exercise the option to promote a hostile renegotiation of foreign debt, or exogenous, due to a shock to sovereign rulers' preferences.

In the model, emerging market stocks are priced at a discount relative to otherwise identical stocks not subject to country risk. The discount varies from stock to stock and depends on the average yield spread on sovereign debt. The discount reflects not only the likelihood of a negative macroeconomic regime change but also global risk aversion, because country risk is priced. Country risk receives compensation because the negative emerging market regime change may be endogenously associated with bad states of the global economy. Therefore, changes in the emerging market discount are driven by changes in the likelihood of a regime change in the emerging market stock cash flows, and changes in emerging market stocks' systematic risk. This rationalization is fundamentally different from Bekaert et al. (2008), who explain changes in the emerging market discount with exogenous changes in the pricing kernel that applies to emerging market stocks. Further research is needed to empirically separate these two alternative explanations for changes in the emerging market stock discount.

I perform a simple evaluation of the model's implications using data from nine emerging markets. Most regressions support the model's qualitative predictions about second moment of securities' returns. Such regressions confirm that, as sovereign yield spreads increase, emerging market stocks tend to become more volatile in absolute terms, less volatile relative to sovereign bonds, and more correlated with sovereign bonds. To investigate the model's quantitative implications, I calibrate the model to Brazil's aggregate stock market. Calibrated with reasonable parameters, the model matches important aspects of Brazilian data from January 1998 to December 2007. More specifically, when the model is evaluated at the median sovereign spread in the period, the model-implied stock volatility, ratio between stock and bond volatilities and correlation between bond and stock returns are equal to the corresponding median values in the data. My calibration indicates that the median discount embedded in Brazilian stock prices from January 1998 to December 2007 was 54.1\%.

Two interesting extensions are left for future research. First, estimating model parameters using the time series of an empirical proxy of the value discount. This can be done using Equation (6), which provides a structural link between the sovereign yield spread and the value discount. A promising candidate for the empirical proxy of the value discount is the industry-adjusted P/E differential between an emerging country and developed ones, proposed by Bekaert et al. (2008). Second, estimating model parameters in order to match realized frequencies of sovereign default/renegotiation, as in the papers by Huang and Huang (2003) and Leland (2004). 


\section{Acknowledgments}

I am grateful to Pierre Collin-Dufresne, Greg Duffee, Rich Lyons, and Mark Seasholes for suggestions and encouragement. I also benefited from discussions with Michael Brennan, Bob Goldstein, Ayse Imrohoroglu, Philippe Jorion, Hayne Leland, Francis Longstaff, Christine Parlour, Eli Remolona, Mark Rubinstein, Jacob Sagi, Richard Stanton, Johan Walden, and Fernando Zapatero. Financial support from CAPES is gratefully acknowledged.

\section{Appendix A. Proofs}

Lemma A.1. Let $Y_{t}$ be a GBM with trend $\mu$ and volatility $\sigma$, and let $0<\delta<\mu$. Then,

$$
E_{t}\left[\int_{t}^{\infty} e^{-\delta(s-t)} Y_{s} \mathrm{~d} s\right]=\frac{Y_{t}}{\mu-\delta}
$$

Proof. Since $Y_{t}$ is a GBM, $Y_{S}=Y_{t} e^{\left(\mu-\frac{1}{2} \sigma^{2}\right)(s-t)+\sigma \sqrt{s-t} Z}$, where $Z$ is a standard normal random variable. We can interchange the integrals and write

$$
E_{t}\left[\int_{t}^{\infty} e^{-\delta(s-t)} Y_{s} \mathrm{~d} s\right]=Y_{t} \int_{t}^{\infty} e^{-\delta(s-t)} e^{\left(\mu-\frac{1}{2} \sigma^{2}\right)(s-t)} E_{S}\left[e^{\sigma \sqrt{s-t} Z}\right] \mathrm{d} s
$$

Substitute $E_{s}\left[e^{\sigma \sqrt{s-t} Z}\right]=e^{\frac{1}{2} \sigma^{2}(s-t)}$, to get $E_{t}\left[\int_{t}^{\infty} e^{-\delta(s-t)} Y_{S} \mathrm{~d} s\right]=Y_{t} \int_{t}^{\infty} e^{-(\delta-\mu)(s-t)} \mathrm{d} s=\frac{Y_{t}}{\mu-\delta}$.

Lemma A.2. Let $Y_{t}$ be a GBM with trend $\mu$ and volatility $\sigma$. Let $\bar{Y}<Y_{t}$ and $T=\min \left\{s: Y_{s}=\bar{Y}\right\}$. Then

$$
E_{t}\left[e^{-\delta(T-t)}\right]=\left(\frac{Y_{t}}{\bar{Y}}\right)^{\theta}
$$

where $\theta$ is defined in Proposition 1.

Proof. See Shreve (2004).

Proof of Proposition 1. The problem of sovereign rulers at time $t$ is:

$$
\sup _{T}\left\{E_{t}\left[\int_{t}^{T} e^{-\delta(s-t)}\left(Y_{S}-c\right) \mathrm{d} s\right]+E_{t}\left[\int_{T}^{\infty} e^{-\delta(s-t)}\left(Y_{S}-\bar{c}\right) \mathrm{d} s\right]\right\}
$$

This is a standard optimal stopping problem in a GBM framework. The optimal $T$ is the first time the process hits a boundary $\bar{Y}: T=\min \left\{s: Y_{S}=\bar{Y}\right\}$ (see Shreve, 2004). For a non-trivial solution in our case, $\bar{Y}$ is below the initial level $Y_{t}$. Using the strong Markov property of the GBM and Lemmas A.1 and A.2, the first term of the maximand can be written as:

$$
\begin{aligned}
E_{t}\left[\int_{t}^{T} e^{-\delta(s-t)}\left(Y_{S}-c\right) \mathrm{d} s\right] & =E_{t}\left[\int_{t}^{\infty} e^{-\delta(s-t)}\left(Y_{S}-c\right) \mathrm{d} s\right]-E_{t}\left[\int_{T}^{\infty} e^{-\delta(s-t)}\left(Y_{S}-c\right) \mathrm{d} s\right] \\
& =\frac{Y_{t}}{\delta-\mu_{y}}-\frac{c}{\delta}-E_{t}\left[\mathrm{e}^{-\delta(T-t)}\right] E_{T}\left[\int_{T}^{\infty} \mathrm{e}^{-\delta(s-t)}\left(Y_{S}-c\right) \mathrm{d} s\right] \\
& =\frac{Y_{t}}{\delta-\mu_{y}}-\frac{c}{\delta}-\left(\frac{Y_{t}}{\bar{Y}}\right)^{\theta}\left(\frac{\bar{Y}}{\delta-\mu_{y}}-\frac{c}{\delta}\right) .
\end{aligned}
$$


The second term of the maximand is:

$$
E_{t}\left[\int_{T}^{\infty} e^{-\delta(s-t)}\left(Y_{S}-\bar{c}\right) \mathrm{d} s\right]=E_{t}\left[e^{-\delta(T-t)}\right] E_{T}\left[\int_{T}^{\infty} e^{-\delta(s-t)}\left(Y_{s}-\bar{c}\right) \mathrm{d} s\right]=\left(\frac{Y_{t}}{\bar{Y}}\right)^{\theta}\left(\frac{\bar{Y}}{\delta-\overline{\mu_{y}}}-\frac{\bar{c}}{\delta}\right) .
$$

Therefore, the sovereign rulers' problem is:

$$
\max _{\bar{Y}}\left\{\frac{Y_{t}}{\delta-\mu_{y}}-\frac{c}{\delta}-\left(\frac{Y_{t}}{\bar{Y}}\right)^{\theta}\left(\frac{\bar{Y}}{\delta-\mu_{y}}-\frac{c}{\delta}\right)+\left(\frac{Y_{t}}{\bar{Y}}\right)^{\theta}\left(\frac{\bar{Y}}{\delta-\overline{\mu_{y}}}-\frac{\bar{c}}{\delta}\right)\right\}
$$

which reduces to:

$$
\max _{\bar{Y}}\left(\frac{1}{\bar{Y}}\right)^{\theta}\left[\frac{c-\bar{c}}{\delta}-\frac{\mu_{y}-\overline{\mu_{y}}}{\left(\delta-\mu_{y}\right)\left(\delta-\overline{\mu_{y}}\right)} \bar{Y}\right]
$$

whose FOC gives Equation (1).

Proof of Proposition 2. The proof uses techniques in Dixit and Pindyck (1994) and Leland (1998). First, I first find the total value of outstanding sovereign debt after the hostile renegotiation of foreign debt, then I find the value before the hostile renegotiation.

Denote the time $t$ value of a sovereign bond issued at the hostile renegotiation by $\overline{B_{t}^{0}}$. Note that $\overline{B_{t}^{0}}$ is independent of $Y_{t}$ because the hostile renegotiation has already occurred. Under the risk-neutral measure $Q$ the instantaneous expected return on the sovereign bond is the risk-free rate. Thus, $\overline{B_{t}^{0}}=e^{-r d t} E_{t}^{Q}\left[\overline{B_{t}^{0}}+d \overline{B_{t}^{0}}\right]+e^{-m t} \bar{c} d t$, where $\bar{c}=\overline{c_{p}}+m \bar{p}$. Using the fact that $d t$ is infinitesimally small, we can write

$$
\overline{B_{t}^{0}}=(1-r d t)\left\{\overline{B_{t}^{0}}+E_{t}^{Q}\left[d \overline{B_{t}^{0}}\right]\right\}+e^{-m t} \bar{c} d t=\overline{B_{t}^{0}}+\frac{d \overline{B_{t}^{0}}}{d t} d t-r \overline{B_{t}^{0}} d t+e^{-m t} \bar{c} d t .
$$

Crossing out $\overline{B_{t}^{0}}$ in both sides of the equation above gives

$$
\frac{d \overline{B^{0}}}{d t}=r \overline{B^{0}}-e^{-m t} \bar{c}
$$

Following Leland (1998), define $\overline{B_{t}}=e^{m t} \overline{B_{t}^{0}}$. Note that $\overline{B_{t}}$ is the total value of outstanding debt at time $t$. Because $\overline{B_{t}}$ receives a constant payment $\bar{c}$, it is independent of $t$. Thus, $d \bar{B} / d t=0$. Using the definition of $\overline{B_{t}}$,

$$
e^{m t} \frac{d \overline{B^{0}}}{d t}+m e^{m t} \overline{B_{t}^{0}}=0 .
$$

Substitute Equation (8) in the equation immediately above, then use $\overline{B_{t}^{0}}=e^{-m t} \overline{B_{t}}$ to get $\overline{B_{t}}=\bar{c} /(r+m)$.

Now denote the time $t$ value of a sovereign bond issued at time 0 by $B_{t}^{0}$. Under the risk-neutral measure $Q$ the instantaneous expected return on the sovereign bond is the risk-free rate. Thus, $B_{t}^{0}=e^{-r d t} E_{t}^{Q}\left[B_{t}^{0}+d B_{t}^{0}\right]+e^{-m t} c d t$, where $c=c_{p}+m p$. Knowing that the drift of $Y_{t}$ under $Q$ is $\mu_{y}-\lambda \sigma_{y} \rho_{y}$, we have:

$$
\begin{aligned}
B_{t}^{0} & =(1-r d t)\left\{\eta d t\left[\overline{B_{t}^{0}}+E_{t}^{Q}\left[d \overline{B_{t}^{0}}\right]\right]+(1-\eta d t)\left[B_{t}^{0}+E_{t}^{Q}\left[d B_{t}^{0}\right]\right]\right\}+e^{-m t} c d t \\
& =(1-r d t)\left\{\eta \overline{B_{t}^{0}} d t+B_{t}^{0}+\left[\left(\mu_{y}-\lambda \sigma_{y} \rho_{y}\right) Y_{t} \frac{\partial B_{t}^{0}}{\partial Y_{t}}+\frac{1}{2} \sigma_{y}^{2} Y_{t}^{2} \frac{\partial^{2} B_{t}^{0}}{\partial Y_{t}^{2}}\right] d t-\eta B_{t}^{0} d t\right\}+e^{-m t} c d t \\
& =B_{t}^{0}+\eta\left(\overline{B_{t}^{0}}-B_{t}^{0}\right) d t+\left[\left(\mu_{y}-\lambda \sigma_{y} \rho_{y}\right) Y_{t} \frac{\partial B_{t}^{0}}{\partial Y_{t}}+\frac{1}{2} \sigma_{y}^{2} Y_{t}^{2} \frac{\partial^{2} B_{t}^{0}}{\partial Y_{t}^{2}}\right] d t-r B_{t}^{0} d t+e^{-m t} c d t
\end{aligned}
$$

Crossing out $B_{t}^{0}$ in both sides and using the fact that $\overline{B_{t}^{0}}=e^{-m t}(\bar{c} /(r+m))$ gives the following PDE: 


$$
\frac{1}{2} \sigma_{y}^{2} Y^{2} \frac{\partial^{2} B^{0}}{\partial Y^{2}}+\left(\mu_{y}-\lambda \sigma_{y} \rho_{y}\right) Y \frac{\partial B^{0}}{\partial Y}-(r+\eta) B^{0}+\eta e^{-m t} \frac{\bar{c}}{r+m}+e^{-m t} c=0 .
$$

Following Leland (1998) again, define $B_{t}=e^{m t} B_{t}^{0}$. Note that $B_{t}$ is the total value of outstanding debt at a future time $t$ prior to the hostile renegotiation. Because $B_{t}$ receives a constant payment $c$, it is independent of $t$. Substitute $e^{-m t} B_{t}$ for $B_{t}^{0}$ in the PDE above to get

$$
\frac{1}{2} \sigma_{y}^{2} Y^{2} \frac{\partial^{2} B}{\partial Y^{2}}+\left(\mu_{y}-\lambda \sigma_{y} \rho_{y}\right) Y \frac{\partial B}{\partial Y}-(r+\eta+m) B+\eta \frac{\bar{c}}{r+m}+c=0 .
$$

The solution $B(Y)$ has to satisfy two boundary conditions:

i) $\lim _{Y \rightarrow \bar{Y}} B(Y)=\bar{B}_{t}=\frac{\bar{c}}{r+m}$;

ii) $\lim _{Y \rightarrow \infty} B(Y)=\frac{\frac{\eta \bar{c}}{r+m}+c}{r+\eta+m}$.

The function in Equation (2) solves the differential equation (9) and satisfies the boundary conditions above. The following paragraphs explain how to obtain boundary condition ii).

When $Y \rightarrow \infty$, the probability that $Y_{t}$ will hit the barrier $\bar{Y}$ is zero. In this case, only the jump probability affects the price of a sovereign bond $B_{t}^{0}$. Under the risk-neutral measure $Q$ the instantaneous expected return on the sovereign bond is the risk-free rate. Thus, $B_{t}^{0}=$ $e^{-r d t} E_{t}^{Q}\left[\overline{B_{t}^{0}}+d \overline{B_{t}^{0}}\right]+e^{-m t} c d t$. Thus, when $Y \rightarrow \infty$ we have,

$$
\begin{aligned}
B_{t}^{0} & =(1-r d t)\left\{\eta d t\left[\overline{B_{t}^{0}}+E_{t}^{Q}\left[d \overline{B_{t}^{0}}\right]\right]+(1-\eta d t)\left[B_{t}^{0}+E_{t}^{Q}\left[d B_{t}^{0}\right]\right]\right\}+e^{-m t} c d t \\
& =(1-r d t)\left\{\eta \overline{B_{t}^{0}} d t+B_{t}^{0}+\frac{d B_{t}^{0}}{d t} d t-\eta B_{t}^{0} d t\right\}+e^{-m t} c d t \\
& =B_{t}^{0}+\eta\left(\overline{B_{t}^{0}}-B_{t}^{0}\right) d t+\frac{d B_{t}^{0}}{d t} d t-r B_{t}^{0} d t+e^{-m t} c d t
\end{aligned}
$$

Crossing out $B_{t}^{0}$ in both sides and using the fact that $\overline{B_{t}^{0}}=e^{-m t \frac{\bar{c}}{r+m}}$ gives

$$
\frac{d B_{t}^{0}}{d t}=(r+\eta) B_{t}^{0}-e^{-m t}\left(c+\frac{\eta \bar{c}}{r+m}\right) .
$$

Because $B_{t}=e^{m t} B_{t}^{0}$ receives a constant payment $c$ prior to the hostile renegotiation, $B_{t}^{0}$ is also independent of $t$ when $Y \rightarrow \infty$. Therefore, when $Y \rightarrow \infty$ we have $d B / d t=0$. Using the definition of $B_{t}$

$$
e^{m t} \frac{d B^{0}}{d t}+m e^{m t} B_{t}^{0}=0
$$

Substitute Equation (10) in the equation immediately above, then use $B_{t}^{0}=e^{-m t} B_{t}$ to get boundary condition ii) of Equation (9).

If sovereign debt was riskless, its time $t$ value would be $B_{t}^{\text {riskless }}=\int_{t}^{\infty} e^{-r(u-t)} e^{-m(u-t)} c \mathrm{~d} u=\frac{c}{r+m}$. The $m$ term in the denominator reflects the fact that debt outstanding at time $t$ is not a perpetuity because it is exponentially amortized over time at a rate $m$. The average sovereign yield spread is the spread $S_{t}$ such that $B_{t}=c /\left(r+S_{t}+m\right)$, therefore $S_{t}=\left(c / B_{t}\right)-(r+m)$. Substituting Equation (2) for $B_{t}$ gives Equation (4). The spread is always decreasing on $Y_{t}$, so we can also express $Y_{t}$ as a function of $S_{t}$ :

$$
Y_{t}=\bar{Y}\left[\frac{S_{t}\left(\frac{1+\frac{\eta}{r+m} \frac{\bar{c}}{c}}{1-\frac{\bar{c}}{c}}\right)-\eta}{S_{t}+r+m}\right]^{\frac{1}{\beta}}
$$


Proof of Proposition 3. The proof uses techniques in Dixit and Pindyck (1994). First we find the stock price after the regime change associated with the hostile renegotiation of foreign debt, then we find the price before the regime change.

After the hostile renegotiation, the emerging market stock pays a continuous cash flow $X_{t}$, whose risk-neutral drift is $\overline{\mu_{x}}-\lambda \overline{\sigma_{x}} \rho_{x}$. Therefore, by Lemma A.1 the price of the stock is:

$$
\bar{P}_{t}=E_{t}^{Q}\left[\int_{t}^{\infty} e^{-r(s-t)} X_{S}\right]=\frac{X_{t}}{r+\lambda \overline{\sigma_{x}} \rho_{x}-\overline{\mu_{x}}} .
$$

The risk-neutral instantaneous expected return of the emerging market stock before the hostile renegotiation is the risk-free rate. Thus, $P_{t}=e^{-r d t} E_{t}^{Q}\left[P_{t}+d P_{t}\right]+X_{t} d t$. Note that $P_{t}$ is a function of $X_{t}$ and $Y_{t}$, since $Y_{t}$ is the process governing the regime change. Using the fact that $d t$ is infinitesimally small, and knowing that before the hostile renegotiation the $Q$-drifts of $X_{t}$ and $Y_{t}$ are respectively $\mu_{x}-\lambda \sigma_{x} \rho_{x}$ and $\mu_{y}-\lambda \sigma_{y} \rho_{y}$ :

$$
\begin{aligned}
P_{t}= & (1-r d t)\left\{\eta d t\left[\bar{P}_{t}+E_{t}^{Q}\left[d \bar{P}_{t}\right]\right]+(1-\eta d t)\left[P_{t}+E_{t}^{Q}\left[d P_{t}\right]\right]\right\}+X_{t} d t \\
= & (1-r d t)\left\{\eta \bar{P}_{t} d t+P_{t}+\left[\left(\mu_{x}-\lambda \sigma_{x} \rho_{x}\right) X_{t} \frac{\partial P_{t}}{\partial X_{t}}+\frac{1}{2} \sigma_{x}^{2} X_{t}^{2} \frac{\partial^{2} P_{t}}{\partial X_{t}^{2}}\right] d t+\left[\left(\mu_{y}-\lambda \sigma_{y} \rho_{y}\right) Y_{t} \frac{\partial P_{t}}{\partial Y_{t}}\right.\right. \\
& \left.\left.+\frac{1}{2} \sigma_{y}^{2} Y_{t}^{2} \frac{\partial^{2} P_{t}}{\partial Y_{t}^{2}}+\sigma_{y} \sigma_{x} \rho_{x y} Y_{t} X_{t} \frac{\partial^{2} P_{t}}{\partial Y_{t} \partial X_{t}}\right] d t-\eta P_{t} d t\right\}+X_{t} d t .
\end{aligned}
$$

Therefore,

$$
\begin{aligned}
P_{t}= & P_{t}+\eta\left(\bar{P}_{t}-P_{t}\right) d t+\left[\left(\mu_{x}-\lambda \sigma_{x} \rho_{x}\right) X_{t} \frac{\partial P_{t}}{\partial X_{t}}+\frac{1}{2} \sigma_{x}^{2} X_{t}^{2} \frac{\partial^{2} P_{t}}{\partial X_{t}^{2}}\right] d t \\
& +\left[\left(\mu_{y}-\lambda \sigma_{y} \rho_{y}\right) Y_{t} \frac{\partial P_{t}}{\partial Y_{t}}+\frac{1}{2} \sigma_{y}^{2} Y_{t}^{2} \frac{\partial^{2} P_{t}}{\partial Y_{t}^{2}}+\sigma_{y} \sigma_{x} \rho_{x y} Y_{t} X_{t} \frac{\partial^{2} P_{t}}{\partial Y_{t} \partial X_{t}}\right] d t-r P_{t} d t+X_{t} d t
\end{aligned}
$$

Crossing out $P_{t}$ on both sides, and substituting in Equation (12) give the following PDE:

$$
\begin{aligned}
& \frac{1}{2} \sigma_{x}^{2} X^{2} \frac{\partial^{2} P}{\partial X^{2}}+\frac{1}{2} \sigma_{y}^{2} Y^{2} \frac{\partial^{2} P}{\partial Y^{2}}+\sigma_{x} \sigma_{y} \rho_{x y} X Y \frac{\partial^{2} P}{\partial X \partial Y} \\
& +\left(\mu_{x}-\lambda \sigma_{x} \rho_{x}\right) X \frac{\partial P}{\partial X}+\left(\mu_{y}-\lambda \sigma_{y} \rho_{y}\right) Y \frac{\partial P}{\partial Y}-(r+\eta) P+\eta \frac{X}{r+\lambda \overline{\sigma_{x}} \rho_{x}-\overline{\mu_{x}}}+X=0
\end{aligned}
$$

The solution $P(X, Y)$ to Equation (13) must satisfy four boundary conditions:

$$
\begin{aligned}
& \text { i) } \lim _{Y \rightarrow \bar{Y}} P\left(X_{t}, Y\right)=\frac{X_{t}}{r+\lambda \overline{\sigma_{x}} \rho_{x}-\overline{\mu_{x}}} \text {; } \\
& \text { ii) } \lim _{X \rightarrow 0} P\left(X, Y_{t}\right)=0 \text {; } \\
& \text { iii) } \lim _{X \rightarrow \infty} \frac{P\left(X, Y_{t}\right)}{X}<\infty \text {; } \\
& \text { iv) } \lim _{Y \rightarrow \infty} P\left(X_{t}, Y\right)=\left(\frac{\frac{\eta}{r+\lambda \rho_{x} \overline{\sigma_{X}}-\overline{\mu_{X}}}+1}{r+\eta+\lambda \rho_{X} \sigma_{X}-\mu_{X}}\right) X_{t} \text {. }
\end{aligned}
$$

The function $P(X, Y)$ below solves the PDE (13) and satisfies the boundary conditions above (we provide more details in Appendix B).

$$
\left.\left.P_{t}=\left[-\left[\frac{Y_{t}}{\bar{Y}}\right]^{\alpha}\left(\frac{\mu_{x}-\overline{\mu_{x}}+\lambda \rho_{x}\left(\overline{\sigma_{x}}-\sigma_{x}\right)}{\left(r+\eta+\lambda \rho_{x} \sigma_{x}-\mu_{x}\right)\left(r+\lambda \rho_{x} \overline{\sigma_{x}}-\overline{\mu_{x}}\right.}\right)\right)+\frac{r+\eta+\lambda \rho_{x} \overline{\sigma_{x}}-\overline{\mu_{x}}}{\left(r+\eta+\lambda \rho_{x} \sigma_{x}-\mu_{x}\right)\left(r+\lambda \rho_{x} \overline{\sigma_{x}}-\overline{\mu_{x}}\right.}\right)\right] X_{t} .
$$


Use Equation (11) and the equation immediately above to get Equation (5). The following paragraph explains how to obtain boundary condition iv).

When $Y \rightarrow \infty$, the probability that $Y_{t}$ will hit the barrier $\bar{Y}$ is zero. Therefore, the stock price $\widehat{P}_{t}$ depends only on $X_{t}$. When $Y \rightarrow \infty$, the instantaneous expected return of the emerging stock under the risk-neutral measure is still the risk-free rate. Therefore, $\lim _{Y \rightarrow \infty} P\left(X_{t}, Y\right)=\widehat{P}_{t}=e^{-r d t} E_{t}^{Q}\left[P_{t}+d P_{t}\right]+X_{t} d t$. Going through the same steps as in Proposition 2 gives:

$$
\frac{1}{2} \sigma_{x}^{2} X^{2} \frac{\partial^{2} \widehat{P}}{\partial X^{2}}+\left(\mu_{x}-\lambda \sigma_{x} \rho_{x}\right) X \frac{\partial \widehat{P}}{\partial X}-(r+\eta) \widehat{P}+\eta \frac{X}{r+\lambda \overline{\sigma_{x}} \rho_{x}-\overline{\mu_{x}}}+X=0 .
$$

The solution $\widehat{P}(X)$ has to satisfy $\lim _{X \rightarrow 0} \widehat{P}(X)=0$ and $\lim _{X \rightarrow \infty} \frac{\widehat{P}(X)}{X}<\infty$. The function $\widehat{P}(X)=\left(\frac{\frac{\eta}{r+\lambda \rho_{X} \overline{\sigma_{X}}-\overline{\mu_{X}}}+1}{r+\eta+\lambda \rho_{X} \sigma_{X}-\mu_{X}}\right) X_{t}$ solves ODE (15) and satisfies such boundary conditions.

Proof of Proposition 4. The Value Discount is defined as $V D_{t}=\left|\left(P_{t} / P_{t}^{\text {no risk }}\right)-1\right|$, where $P_{t}^{\text {no }}$ risk $=X_{t} \mid$ $\left(r+\lambda \sigma_{x} \rho_{x}-\mu_{x}\right)$ is the price of an otherwise identical stock which is not subjected to country risk. Substituting in the expression for $P_{t}^{\text {no risk }}$ above, $P_{t}$ in Equation (5) and using Equation (11) gives Equation (6). By inspection, it is evident that the magnitude of $V D_{t}$ increases with $S_{t}$.

Proof of Proposition 5. By definition, the instantaneous volatility of bond and stock returns and their instantaneous covariances are respectively:

$$
\sigma_{B}=\frac{1}{d t} \sqrt{E_{t}\left[\left(\frac{d B_{t}}{B_{t}}\right)^{2}\right]}, \quad \sigma_{P}=\frac{1}{d t} \sqrt{E_{t}\left[\left(\frac{d P_{t}}{P_{t}}\right)^{2}\right]} \quad \text { and } \quad \sigma_{P B}=\frac{1}{d t} E_{t}\left[\frac{d P_{t}}{P_{t}} \frac{d B_{t}}{B_{t}}\right] .
$$

By Ito's Lemma, the diffusion terms of $d P_{t}$ and $d B_{t}$ are:

$$
\begin{aligned}
d P_{t} & =\frac{\partial P_{t}}{\partial Y_{t}} d Y_{t}+\frac{\partial P_{t}}{\partial X_{t}} d X_{t}+\frac{1 \partial^{2} P_{t}}{2 \partial Y_{t}^{2}}\left(d Y_{t}\right)^{2}+\frac{1 \partial^{2} P_{t}}{2 \partial X_{t}^{2}}\left(d X_{t}\right)^{2}+\frac{\partial^{2} P_{t}}{\partial Y_{t} \partial X_{t}}\left(d Y_{t}\right)\left(d X_{t}\right), \\
d B_{t} & =\frac{\partial B_{t}}{\partial Y_{t}} d Y_{t}+\frac{1 \partial^{2} B_{t}}{2 \partial Y_{t}^{2}}\left(d Y_{t}\right)^{2}
\end{aligned}
$$

Substituting $d X_{t}$ and $d Y_{t}$ gives the contribution of the diffusion terms to the instantaneous volatilities and covariance. Since $P\left(X_{t}, Y_{t}\right)$ is linear in $X_{t}$, we have $\left(\partial P_{t} / \partial X_{t}\right)\left(X_{t} / P_{t}\right)=1$. We ignore the jump terms in $\sigma_{B}$, $\sigma_{P}$ and $\sigma_{P B}$ because we want to focus on second moments conditioned on the absence of a jump to hostile renegotiation. We have:

$$
\begin{aligned}
& \sigma_{P_{t}}=\sqrt{\sigma_{x}^{2}+\left(\frac{\partial P_{t}}{\partial Y_{t}} \frac{Y_{t}}{P_{t}}\right)^{2} \sigma_{y}^{2}+2\left(\frac{\partial P_{t}}{\partial Y_{t}} \frac{Y_{t}}{P_{t}}\right) \sigma_{x} \sigma_{y} \rho_{x y} .} \\
& \sigma_{B_{t}}=\sqrt{\left(\frac{\partial B_{t}}{\partial Y_{t}} \frac{Y_{t}}{B_{t}}\right)^{2} \sigma_{y}^{2}} . \\
& \sigma_{P B_{t}}=\left(\frac{\partial B_{t}}{\partial Y_{t}} \frac{Y_{t}}{B_{t}}\right)\left[\sigma_{x} \sigma_{y} \rho_{x y}+\left(\frac{\partial P_{t}}{\partial Y_{t}} \frac{Y_{t}}{P_{t}}\right) \sigma_{y}^{2}\right] .
\end{aligned}
$$

Use Equation (5) to write $P_{t}=X_{t}\left(K_{1} Y_{t}^{\alpha}+K_{2}\right)$ with $\alpha<0, K_{1}<0$ and $K_{2}>0$. Therefore,

$$
\frac{\partial P_{t}}{\partial Y_{t}} \frac{Y_{t}}{P_{t}}=\frac{\alpha K_{1} Y_{t}^{\alpha}}{K_{1} Y_{t}^{\alpha}+K_{2}}=\alpha K_{1} Y_{t}^{\alpha} \frac{X_{t}}{P_{t}}>0
$$

Similarly, use Equation (2) to write $B_{t}=K_{3} Y_{t}^{\beta}+K_{4}$ with $\beta<0, K 3<0$ and $K_{4}>0$. Thus: 


$$
\frac{\partial B_{t}}{\partial Y_{t}} \frac{Y_{t}}{B_{t}}=\frac{\beta K_{3} Y_{t}^{\beta}}{K_{3} Y_{t}^{\beta}+K_{4}}=\beta K_{3} Y_{t}^{\beta} \frac{1}{B_{t}}>0 .
$$

From the signs of (19) and (20), we conclude that $\sigma_{P B}$ is always positive. Taking derivatives, we get:

$$
\begin{gathered}
\frac{\partial\left[\frac{\partial P_{t} Y_{t}}{\partial Y_{t} P_{t}}\right]}{\partial Y_{t}}=K_{1} K_{2} \alpha^{2} \frac{Y_{t}^{\alpha-1}}{\left(K_{1} Y_{t}^{\alpha}+K_{2}\right)^{2}}<0, \\
\frac{\partial\left[\frac{\partial B_{t} Y_{t}}{\partial Y_{t} B_{t}}\right]}{\partial Y_{t}}=K_{3} K_{4} \beta^{2} \frac{Y_{t}^{\beta-1}}{\left(K_{3} Y_{t}^{\beta}+K_{4}\right)^{2}}<0 .
\end{gathered}
$$

Since $\left(\partial S_{t} / \partial Y_{t}\right)<0$, Equations (21) and (22) show that the diffusion terms of $\sigma_{P_{t}}, \sigma_{B_{t}}$ and $\sigma_{P B_{t}}$ increase with the sovereign spread. Therefore, conditioned on the absence of a jump, $\sigma_{P_{t}}, \sigma_{B_{t}}$ and $\sigma_{P B_{t}}$ increase with the sovereign yield spread.

To obtain explicit analytical equations for $\sigma_{P}\left(S_{t}\right), \sigma_{B}\left(S_{t}\right)$ and $\sigma_{P B}\left(S_{t}\right)$, use Equations (5), (2) and (11) to get:

$$
\begin{aligned}
\frac{\partial P_{t}}{\partial Y_{t}} \frac{Y_{t}}{P_{t}}\left(S_{t}\right) & =\frac{\alpha}{1-\frac{r+\eta+\lambda \rho_{x} \overline{\sigma_{x}}-\overline{\mu_{x}}}{\mu_{x}-\overline{\mu_{x}}+\lambda \rho_{x}\left(\overline{\sigma_{x}}-\sigma_{x}\right)}\left[\frac{S_{t}+r+m}{S_{t}\left(\frac{1+\frac{\eta}{r+m} \frac{\bar{c}}{\bar{c}}}{1-\frac{\bar{c}}{c}}\right)-\eta}\right]^{\frac{\alpha}{\beta}},} \\
\frac{\partial B_{t}}{\partial Y_{t}} \frac{Y_{t}}{B_{t}}\left(S_{t}\right) & =\frac{\beta}{1-\frac{S_{t}+r+m}{S_{t}-\frac{\eta\left(1-\frac{\bar{c}}{c}\right)}{1+\frac{\eta}{r+m} \frac{\bar{c}}{c}}}} .
\end{aligned}
$$

Now substitute the equations immediately above into Equations (17), (16) and (18) to get $\sigma_{P_{t}}$, $\sigma_{B_{t}}$ and $\sigma_{P B_{t}}$ as analytical functions of $S_{t}$. Taking derivatives on the analytical functions, it can be shown that, conditioned on the absence of a jump, the correlation of bond and stock returns $\rho_{P B}=\sigma_{P B} /\left(\sigma_{P} \sigma_{B}\right)$ increases with the sovereign spread $S_{t}$.

Proof of Proposition 6. Cochrane (2001), for example, shows that the instantaneous expected return of the emerging stock $\mu_{P}=(1 / d t) E_{t}\left[\left(d P_{t} / P_{t}\right)\right]$ is $\mu_{P}=(1 / d t) \operatorname{cov}_{t}\left[\left(d P_{t} / P_{t}\right),-\left(d \Lambda_{t} / \Lambda_{t}\right)\right]$. Since the jump component of price changes is idiosyncratic, only the diffusion terms matter for risk compensation. Applying Ito's Lemma to $d P_{t}$ and calculating the covariance gives $\mu_{P}=r+\lambda\left(\frac{\partial P_{t} X_{t}}{\partial X_{t} P_{t}} \sigma_{x} \rho_{x}+\frac{\partial P_{t} Y_{t}}{\partial Y_{t} P_{t}} \sigma_{y} \rho_{y}\right)$. Using the fact that $\left(\partial P_{t} / \partial X_{t}\right)\left(X_{t} / P_{t}\right)=1$ gives:

$$
\mu_{P}=r+\lambda\left(\sigma_{x} \rho_{x}+\frac{\partial P_{t}}{\partial Y_{t}} \frac{Y_{t}}{P_{t}} \sigma_{y} \rho_{y}\right)
$$

From Equation (19), $\mu_{P}$ is always greater than the risk-free rate. Substituting in Equation (23) gives Equation (7).

\section{Appendix B. Additional details on the solution of the stock price PDE}

We claim that $P(X, Y)$ in Equation (14) solves the stock price PDE in Equation (13), and satisfies its four boundary conditions. The PDE is: 
Table A.1

Market capitalizations and presence in the EMBI+ Index.

\begin{tabular}{lll}
\hline Country & Market capitalization (US \$bi) & Presence in EMBI+ Index \\
\hline China & 4459 & None \\
India & 1815 & None \\
Brazil & 1399 & $01 / 1998-12 / 2007$ \\
South Korea & 1103 & $05 / 1998-06 / 2002$ \\
Russia & 996 & $01 / 1998-12 / 2007$ \\
Taiwan & 701 & None \\
South Africa & 456 & $05 / 2002-12 / 2007$ \\
Mexico & 399 & $01 / 1998-12 / 2007$ \\
Malaysia & 324 & $02 / 2002-11 / 2004$ \\
Turkey & 282 & $08 / 1999-12 / 2007$ \\
Thailand & 213 & None \\
Poland & 208 & $01 / 1998-04 / 2007$ \\
Chile & 208 & None \\
Indonesia & 205 & None \\
Argentina & 124 & $01 / 1998-11 / 2001$ \\
& & $07 / 2005-12 / 2007$ \\
\hline
\end{tabular}

This table presents the total market capitalization (in US dollars) of the largest emerging stock markets at the end of 2007. The table also indicates the period for which the country has been part of J.P. Morgan's EMBI Plus Index from January 1998 to December 2007. Data are from Bloomberg, the World Bank, and J.P. Morgan. Countries are ordered by market capitalization at the end of 2007.

$$
\begin{aligned}
\frac{1}{2} \sigma_{x}^{2} X^{2} \frac{\partial^{2} P}{\partial X^{2}}+ & \frac{1}{2} \sigma_{y}^{2} Y^{2} \frac{\partial^{2} P}{\partial Y^{2}}+\sigma_{x} \sigma_{y} \rho_{x y} X Y \frac{\partial^{2} P}{\partial X \partial Y}+\left(\mu_{x}-\lambda \sigma_{x} \rho_{x}\right) X \frac{\partial P}{\partial X} \\
& +\left(\mu_{y}-\lambda \sigma_{y} \rho_{y}\right) Y \frac{\partial P}{\partial Y}-(r+\eta) P+\eta \frac{X}{r+\lambda \overline{\sigma_{x}} \rho_{x}-\overline{\mu_{x}}}+X=0 .
\end{aligned}
$$

The four boundary conditions are:

$$
\begin{aligned}
\text { i) } & \lim _{Y \rightarrow \bar{Y}} P\left(X_{t}, Y\right)=\frac{X_{t}}{r+\lambda \overline{\sigma_{x}} \rho_{x}-\overline{\mu_{x}}} ; \\
\text { ii) } & \lim _{X \rightarrow 0} P\left(X, Y_{t}\right)=0 ; \\
\text { iii) } & \lim _{X \rightarrow \infty} \frac{P\left(X, Y_{t}\right)}{X}<\infty ; \\
\text { iv) } & \lim _{Y \rightarrow \infty} P\left(X_{t}, Y\right)=\left(\frac{\frac{\eta}{r+\lambda \rho_{x} \overline{\sigma_{x}}-\overline{\mu_{x}}}+1}{r+\eta+\lambda \rho_{x} \sigma_{X}-\mu_{x}}\right) X_{t} .
\end{aligned}
$$

Re-arranging Eq. (14) gives:

where $P=\left(\frac{Y}{\bar{Y}}\right)^{\alpha}\left(\frac{1}{r+\lambda \rho_{x} \overline{\sigma_{x}}-\overline{\mu_{x}}}-\frac{\frac{\eta}{r+\lambda \rho_{x} \overline{\sigma_{x}}-\overline{\bar{\mu}}}+1}{r+\lambda \rho_{x} \sigma_{x}-\mu_{x}}\right) X+\frac{\frac{\eta}{r+\lambda \rho_{x} \overline{\sigma_{x}}-\overline{\overline{\mu_{x}}}}+1}{r+\lambda \rho_{x} \sigma_{x}-\mu_{x}} X$,

$$
\alpha=\frac{1}{2}-\frac{\mu_{y}-\lambda \sigma_{y} \rho_{y}}{\sigma_{y}^{2}}-\frac{\rho_{x y} \sigma_{x}}{\sigma_{y}}-\sqrt{\left(\frac{1}{2}-\frac{\mu_{y}-\lambda \sigma_{y} \rho_{y}}{\sigma_{y}^{2}}-\frac{\rho_{x y} \sigma_{x}}{\sigma_{y}}\right)^{2}+\frac{2}{\sigma_{y}^{2}}\left(r+\eta+\lambda \sigma_{x} \rho_{x}-\mu_{x}\right)}<0 .
$$

Inspecting the equations above, it is evident that the four boundary conditions are satisfied.

We can write the stock price as:

$$
P=P_{1}+P_{2}=K_{1} Y^{\alpha} X+K_{2} X,
$$

where $K_{1}=\frac{1}{\bar{Y}^{\alpha}}\left(\frac{1}{r+\lambda \rho_{x} \overline{\sigma_{x}}-\overline{\mu_{x}}}-\frac{\frac{\eta}{r+\lambda \rho_{x} \overline{\sigma_{x}}-\overline{\mu_{x}}}+1}{r+\lambda \rho_{x} \sigma_{x}-\mu_{x}}\right)$ and $K_{2}=\frac{\frac{\eta}{r+\lambda \rho_{x} \overline{\sigma_{x}}-\overline{\mu_{x}}}+1}{r+\lambda \rho_{x} \sigma_{x}-\mu_{x}}$. 
We claim that the first term $P_{1}$ solves the homogenous part of the PDE. We have:

$$
\begin{aligned}
& \frac{\partial P_{1}}{\partial X}=K_{1} Y^{\alpha} ; \quad \frac{\partial P_{1}}{\partial Y}=\alpha K_{1} Y^{\alpha-1} X \\
& \frac{\partial^{2} P_{1}}{\partial X^{2}}=0 ; \quad \frac{\partial^{2} P_{1}}{\partial X \partial Y}=\alpha K_{1} Y^{\alpha-1} ; \quad \frac{\partial^{2} P_{1}}{\partial Y^{2}}=(\alpha-1) \alpha K_{1} Y^{\alpha-2} X
\end{aligned}
$$

Substituting the derivatives above in the homogenous part of the PDE gives:

$$
\begin{aligned}
& K_{1} Y^{\alpha} X\left[\frac{1}{2} \sigma_{y}^{2}(\alpha-1) \alpha+\sigma_{x} \sigma_{y} \rho_{x y} \alpha+\left(\mu_{x}-\lambda \sigma_{x} \rho_{x}\right)+\left(\mu_{y}-\lambda \sigma_{y} \rho_{y}\right) \alpha-(r+\eta)\right]=0 \\
& \therefore \frac{1}{2} \sigma_{y}^{2} \alpha^{2}+\left(\mu_{y}-\lambda \sigma_{y} \rho_{y}-\sigma_{x} \sigma_{y} \rho_{x y}-\frac{1}{2} \sigma_{y}^{2}\right) \alpha-\left(r+\eta+\lambda \sigma_{x} \rho_{x}-\mu_{x}\right)=0 .
\end{aligned}
$$

By inspection, it is evident that $\alpha$ as defined in Proposition 3 is the negative root of the quadratic equation immediately above. Thus, $P_{1}$ is a solution to the homogenous part of Equation (13).

The derivatives for $P_{2}$ are:

$$
\begin{aligned}
& \frac{\partial P_{2}}{\partial X}=K_{2} ; \quad \frac{\partial P_{2}}{\partial Y}=0 \\
& \frac{\partial^{2} P_{2}}{\partial X^{2}}=0 ; \quad \frac{\partial^{2} P_{2}}{\partial X \partial Y}=0 ; \quad \frac{\partial^{2} P_{2}}{\partial Y^{2}}=0 .
\end{aligned}
$$

Using the fact that $P_{1}$ solves the homogenous part of the PDE, substitute the derivatives for $P=P_{1}+P_{2}$ in Equation (13) to get:

$$
\begin{aligned}
& \left(\mu_{x}-\lambda \sigma_{x} \rho_{x}\right) X K_{2}-(r+\eta) X K_{2}+\left(\frac{\eta}{r+\lambda \overline{\sigma_{x}} \rho_{x}-\overline{\mu_{x}}}+1\right) X \\
& \quad=X\left[\left(\mu_{x}-\lambda \sigma_{x} \rho_{x}-\eta-r\right) K_{2}+\left(\frac{\eta}{r+\lambda \overline{\sigma_{x}} \rho_{x}-\overline{\mu_{x}}}+1\right)\right]=0
\end{aligned}
$$

The second equality comes from the definition of $K_{2}$ a few paragraphs above. Therefore, $P(X, Y)$ in Equation (14) satisfies the stock price PDE in Equation (13) and its four boundary conditions as claimed.

\section{References}

Aguiar, M., Gopinath, G., 2006. Defaultable debt, interest rates and the current account. Journal of International Economics 69, 64-83.

Albuquerque, R., Wang, N., 2008. Agency conflicts, investment, and asset pricing. Journal of Finance 63, 1-40.

Arellano, C., 2008. Default risk and income fluctuations in emerging economies. American Economic Review, 98, 690-712

Backus, D.K., Kehoe, P.J., Kydland, F.E., 1992. International real business cycles. Journal of Political Economy 100, 745-775.

Bakshi, G., Chen, Z., 2005. Stock valuation in dynamic economies. Journal of Financial Markets 8, 111-151.

Bailey, W., Chung, P., 1995. Exchange rate fluctuations, political risk, and stock returns: some evidence from an emerging market. Journal of Financial and Quantitative Analysis 30, 541-561.

Bailey, W., Chung, P., Kang, J.K., 1999. Foreign ownership restrictions and equity price premiums: what drives the demand for cross-border investments? Journal of Financial and Quantitative Analysis 34, 489-511.

Bailey, W., Jagtiani, J., 1994. Foreign ownership restrictions and stock prices in the Thai market. Journal of Financial Economics 36, 57-87.

Bansal, R., Dahlquist, M., 2002. Expropriation Risk and Return in Global Capital Markets. Unpublished working paper. Duke University.

Bekaert, G., 1995. Market integration and investment barriers in emerging equity markets. The World Bank Economic Review 9 , 75-107.

Bekaert, G., Harvey, C.R., 1995. Time-varying world market integration. Journal of Finance 50, 403-444.

Bekaert, G., Harvey, C.R., 1997. Emerging equity market volatility. Journal of Financial Economics 43, 29-77.

Bekaert, G., Harvey, C.R., 2000. Foreign speculators and emerging equity markets. Journal of Finance 55, 565-614.

Bekaert, G., Harvey, C.R., 2002. Research in emerging markets' finance: looking to the future. Emerging Markets Review 3, 429-448.

Bekaert, G., Harvey, C.R., 2003. Emerging markets finance. Journal of Empirical Finance 10, 3-55.

Bekaert, G., Harvey, C.R., Lumsdaine, R., 2002. Dating the integration of world capital markets. Journal of Financial Economics $65,203-247$. 
Bekaert, G., Erb, C.B., Harvey, C.R., Viskanta, T.E., 1997. What matters for emerging market investments. Emerging Markets Quarterly Summer, 17-46.

Bekaert, G., Harvey, C.R., Lundblad, C., Siegel, S., 2007. Global growth opportunities and market integration. Journal of Finance 62, 1081-1137.

Bekaert, G., Harvey, C.R., Lundblad, C., Siegel, S., 2008. What Segments Equity Markets? Unpublished working paper. Duke University.

Berk, J., Green, R.C., Naik, V., 1999. Optimal investment, growth options, and security returns. Journal of Finance 54, $1553-1607$.

Bhamra, H., Kuehn, L., Strebulaev, I., 2007. The Levered Equity Premium and Credit Spreads: a Unified Framework. Unpublished working paper. University of British Columbia.

Bonomo, M.A., Garcia, R., 2001. Tests of conditional asset pricing models in the Brazilian stock market. Journal of International Money and Finance 20, 71-90.

Brennan, M.J., Wang, A.W., Xia, Y., 2004. Estimation and test of a simple model of intertemporal capital asset pricing. Journal of Finance 69, 1743-1775.

Bulow, J., Rogoff, K.S., 1989. A constant recontracting model of sovereign debt. Journal of Political Economy 97, 155-178.

Carrieri, F., Errunza, V.R., Hogan, K., 2007. Characterizing world market integration through time. Journal of Financial and Quantitative Analysis 42, 915-940.

Carrieri, F., Errunza, V.R., Majerbi, B., 2006. Does emerging market exchange risk affect global equity prices? Journal of Financial and Quantitative Analysis 41, 511-540.

Chari, A., Henry, P.B., 2004. Risk sharing and asset prices: evidence from a natural experiment. Journal of Finance 59, 1295-1324.

Chen, H., 2007. Macroeconomic Conditions and the Puzzles of Credit Spreads and Capital Structure. Unpublished working paper. University of Chicago.

Cherian, J.A., Perotti, E., 2001. Option pricing and foreign investment under political risk. Journal of International Economics 55, 359-377.

Claessens, S., Pennacchi, G., 1996. Estimating the likelihood of Mexican default from the market prices of Brady bonds. Journal of Financial and Quantitative Analysis 31, 109-126.

Cochrane, J.H., 2001. Asset Pricing. Princeton University Press.

Cohen, D., Sachs, J., 1985. Growth and external debt under risk of debt repudiation. European Economic Review 30, 529-560.

Damodaran, A., 2003. Measuring Company Exposure to Country Risk: Theory and Practice. Unpublished working paper. New York University.

Dixit, A.K., Pindyck, R.S., 1994. Investment under Uncertainty. Princeton University Press.

Dooley, M.P., 2000. Can output losses following financial crises be avoided? NBER Working Paper No. 7531.

Domowitz, I., Glen, J., Madhavan, A., 1997. Market segmentation and stock prices: evidence from an emerging market. Journal of Finance 52, 1059-1085.

Duffie, D., Pedersen, L., Singleton, K.J., 2003. Modeling sovereign yield spreads: a case study of Russian debt. Journal of Finance 55, 119-159.

Eaton, J., Fernandez, R., 1995. Sovereign Debt. In: Handbook of International Economics, vol. 3. North Holland.

Eaton, J., Gersovitz, M., 1981. Debt with potential repudiation: theoretical and empirical analyses. Review of Economic Studies 48, 289-389.

Edison, H., Warnock, F., 2003. A simple measure of the intensity of capital controls. Journal of Empirical Finance 10, 81-103.

Erb, C.B., Harvey, C.R., Viskanta, T.E., 1995. Country risk and global equity selection. Journal of Portfolio Management Winter, 2946.

Erb, C.B., Harvey, C.R., Viskanta, T.E., 1996a. Expected return and volatility in 135 countries. Journal of Portfolio Management Spring, 46-58.

Erb, C.B., Harvey, C.R., Viskanta, T.E., 1996b. Political risk, financial risk and economic risk. Financial Analysts Journal 52, 28-46.

Erb, C.B., Harvey, C.R., Viskanta, T.E., 1998. Country Risk in Global Financial Management. Research Foundation of the AIMR.

Errunza, V.R., Losq, E., 1985. International asset pricing under mild segmentation: theory and test. Journal of Finance 40, 105124.

Errunza, V.R., Miller, D.P., 2000. Market segmentation and the cost of capital in international equity markets. Journal of Financial and Quantitative Analysis 35, 577-600.

Estrada, J., 2007. Discount rates in emerging markets: four models and an application. Journal of Applied Corporate Finance 19, 72-77.

François, P., 2006. Package Restructuring and the Pricing of Sovereign Debt. Unpublished working paper. HEC, Montreal.

Forbes, K.J., Rigobon, R., 2002. No contagion, only interdependence: measuring stock market comovements. Journal of Finance 57, 2223-2261.

Galai, D., Masulis, R.W., 1976. The option pricing model and the risk factor of stock. Journal of Financial Economics 3, 53-81.

Gendreau, B., Heckman, L., 2003. Sovereign spreads and emerging market equity returns. Journal of Portfolio Management Fall, 104-114.

Goetzmann, W.N., Jorion, P., 1999. Re-emerging markets. Journal of Financial and Quantitative Analysis 34, 1-32.

Harvey, C.R., 1995. Predictable risk and returns in emerging markets. Review of Financial Studies 8, 773-816.

Harvey, C.R., 2006. Risk Analysis and Project Evaluation. Presentation available on the author's website.

Hayri, A., 2000. Debt relief. Journal of International Economics 52, 137-152.

Henry, P.B., 2000. Stock market liberalization, economic reform, and emerging market equity prices. Journal of Finance 55, 529564.

Hilscher, J., Nosbusch, Y., 2007. Determinants of Sovereign Risk: Macroeconomic Fundamentals and the Pricing of Sovereign Debt. Unpublished working paper. Harvard University.

Huang, J., Huang, M., 2003. How Much of the Corporate-Treasury Yield Spread is Due to Credit Risk? Unpublished working Paper. Stanford University.

Keck, T., Levengood, E., Longfield, A., 1998. Using discounted cash flow analysis in an international setting. Journal of Applied Corporate Finance 11, 82-99.

Kehoe, P.J., Perri, F., 2002. International business cycles with endogenous incomplete markets. Econometrica 70, 907-928. 
Kulatilaka, N., Marcus, A.J., 1987. A model of strategic default of sovereign debt. Journal of Economic Dynamics and Control 11, 483-498.

Leland, H.E., 1994. Corporate debt value, bond covenants and optimal capital structure. Journal of Finance 49, 987-1019.

Leland, H.E., 1998. Agency costs, risk management, and capital structure. Journal of Finance 53, 1213-1242.

Leland, H.E., 2004. Predictions of default probabilities in structural models of debt. Journal of Investment Management 2, 16-40.

Leuz, C., Nanda, D., Wysocki, P.D., 2003. Earnings management and investor protection: an international comparison. Journal of Financial Economics 69, 505-527.

Longstaff, F.A., Piazzesi, M., 2004. Corporate earnings and the equity premium. Journal of Financial Economics 74, 401-421.

Longstaff, F.A., Mithal, S., Neis, E., 2005. Corporate yield spreads: default risk or liquidity? New evidence from the credit default swap market. Journal of Finance 60, 2213-2253.

Mariscal, J.O., Lee, R.M., 1993. The Valuation of Mexican Stocks: an Extension of the Capital Asset Pricing Model. Goldman Sachs, New York. Mimeo.

Martell, R., Stulz, R.M., 2003. Equity market liberalizations as country IPOs. American Economic Review 93, 97-101.

Merton, R.C., 1976. On estimating the expected return on the market. Journal of Financial Economics 8, 323-361.

Nishiotis, G., 2004. Do indirect investment barriers contribute to capital market segmentation? Journal of Financial and Quantitative Analysis 39, 613-630.

Pan, J., Singleton, K.J., 2008. Default and recovery implicit in the term structure of sovereign CDS spreads. Journal of Finance 63, 2345-2384.

Phylaktis, K., Ravazzolo, F., 2002. Measuring financial and economic integration with equity prices in emerging markets. Journal of International Money and Finance 21, 879-904.

Rose, A.K., 2005. One reason countries pay their debts: renegotiation and international trade. Journal of Development Economics 77, 189-206.

Remolona, E.M., Scatigna, M., Wu, E., 2008. The dynamic pricing of sovereign risk in emerging markets: fundamentals and risk aversion. Journal of Fixed Income 17, 57-71.

Scholtens, B., 1999. On the co-movement of bond yield spreads and country credit ratings. Journal of Fixed Income March, 99-103.

Shreve, S.E., 2004. Stochastic Calculus for Finance II: Continuous-Time Models. Springer.

Stulz, R.M., 1981. On the effects of barriers to international investment. Journal of Finance 36, 923-934.

Stulz, R.M., 2005. The limits of financial globalization. Journal of Finance 60, 1595-1638.

Sturzenegger, F., Zettelmeyer, J., 2007. Creditors losses versus debt relief: results from a decade of sovereign debt crises. Journal of the European Economic Association 5, 343-351.

Westphalen, M., 2001. Valuation of Sovereign Debt with Strategic Defaulting and Re-Scheduling. Unpublished working paper. HEC, Lausanne.

Yue, V., 2006. Sovereign Default and Debt Renegotiation. Unpublished working paper. New York University. 